

\section{Sumário}

Ordenamiento ambiental del terRitorio y participación CiUdadana en Argentina: aportes posibles DESDE EL DERECHO 2

María Valeria Berros

Matéria ambiental nos tribunais da Austrália e nova Zelândia ................................................... 17 Marcio Oliveira Portella

Conservação da BIODIVERSIDADE E POLÍtICAS PÚbLICAS PARA AS ÁREAS PROTEGIDAS NO BRASIL: DESAFIOS E

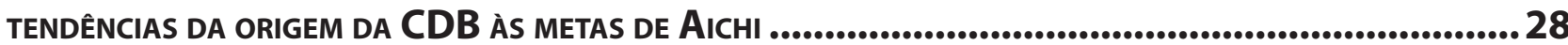

Ana Paula Leite Prates e Marta de Azevedo Irving

Dimensões linguísticas dA DESIGUALDADE No BrASIL: OS DIVERSOS NOMES LEGAIS DE UM MESMO FENÔMENo

Jefferson Carús Guedes

ECONOMIA, ÉTICA E TRIBUTAÇÃO: DOS FUNDAMENTOS DA DESIGUALDADE

Rafael Köche e Marciano Buffon

A REPARTIÇÃO de RENDAS ENTRE OS ENTES DA FEDERAÇÃO E SUA REPERCUSSÃo NA CARACTERIZAÇÃo DO FEDERALISMO BRASILEIRO: UMA INVESTIGAÇÃO ACERCA DO DESENVOLVIMENTO DO FEDERALISMO FISCAL-FINANCEIRO NO BRASIL.

Raquel Mousinho de Moura Fé

UMA AVALIAÇÃO DO ÍNDICE DE INCLUSÃO FINANCEIRA NOS ESTADOS DO NORDESTE BRASILEIRO

Diego Araujo Reis e Osvaldo Sousa Ventura

Fatores determinantes do Índice de Desenvolvimento Humano dos Municípios do Estado de São

PaUlo

Leandro Campi Prearo, Maria Clara Maraccini e Maria do Carmo Romeiro

As políticas públicas de acesso e difusão da cultura no Brasil e o caso do Programa Nacional de Apoio à Cultura. 157

Telma Rocha Lisowski

MoldANDO A "RESERVA do POSSível" NO TEMPO: A SUSTENTABILIDADE FISCAL COMO DIREITO DIFUSO FUNDAMENTAL. 171

Leonardo Romero Marino 
O PODER JUDICIÁRIO E A EFETIVAÇÃO DO DIREITO À SAÚDE

João Luis Nogueira Matias e Águeda Muniz

EDUCAÇÃo SUPERIOR NO BRASIL: OFERTA NA OMC, UMA REFLEXÃO DESMISTIFICADA, COM BASE EM DADOS ESTATÍSTICOS 208

Marcel Vitor Guerra

A GARANTIA DO DIREITO À EDUCAÇÃO DE CRIANÇAS E ADOLESCENTES NO CONTEXTO DAS POLÍTICAS PÚBLICAS BRASILEIRAS

André Viana Custódio e Rafael Bueno da Rosa Moreira

A POLÍCIA JUDICIÁRIA E O COMBATE À CRIMINALIDADE

Júlio Lopes Hott

Processo eleitoral e políticas Públicas: influÊnCias ReCíProcas.

Pablo Malheiros da Cunha Frota

SOCIEDADES PRIMITIVAS E DIREITO CONTEMPORÂNEO: DE QUE FORMA A JUSTIÇA TRIBAL PODE NOS AJUDAR A REPENSAR A NOSSA JUSTIÇA 303

Amanda Rodrigues e Tiago Themudo

DIREITO PRIVADO, JUSTIÇA DISTRIBUTIVA E O ARGUMENTO DA DUPLA DISTORÇÃO: UMA REVISÃO DA LITERATURA ...........318 Leandro Martins Zanitelli

DistorçõES NO CONTROLE CADASTRAL DAS ENTIDADES SINDICAIS E CONTRIBUIÇÃO SINDICAL Ricardo Bravo

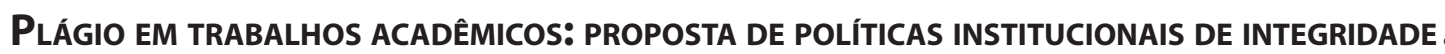
354 Maria Edelvacy Pinto Marinho e Marcelo Dias Varella 


\title{
Conservação da biodiversidade e políticas públicas para as áreas protegidas no Brasil: desafios e tendências da origem da CDB às metas de Aichi*
}

\author{
Biodiversity conservation and public policies \\ for protected areas in Brazil: challenges and \\ trends from the origin of the CBD until the \\ Aichi targets
}

Ana Paula Leite Prates**

Marta de Azevedo Irving***

\section{Resumo}

O Brasil apresenta a mais rica biodiversidade mundial e foi o primeiro país a assinar a Convenção de Diversidade Biológica que consagrou as áreas protegidas como um dos principais instrumentos para a conservação da biodiversidade. Com base nesse contexto, o objetivo do artigo é interpretar, criticamente, avanços, desafios e tendências das políticas públicas para as áreas protegidas no Brasil, à luz dos compromissos assumidos pelo país no âmbito da Convenção da Diversidade Biológica desde a sua origem até as atuais Metas de Aichi, acordadas na COP10 em Nagoya, Japão (2010) para se conter a perda global de biodiversidade. Com esse objetivo, o trabalho incide prioritariamente sobre a análise da Meta 11 de Aichi, referente às áreas protegidas, frente aos obstáculos e desafios de um país emergente. $\mathrm{O}$ artigo foi desenvolvido com base em pesquisa bibliográfica e documental e também tem como inspiração as informações obtidas por meio da participação direta em algumas das Conferencias das Partes, registradas em caderno de campo e sistematizadas para análise retrospectiva de processo. Pode-se concluir, a partir da pesquisa realizada, que o Brasil dispõe de inúmeros instrumentos de políticas públicas voltados à conservação da biodiversidade, em especial às áreas protegidas. No entanto, na atual conjuntura, permanece como desafio central a integração entre as políticas públicas de conservação da biodiversidade e desenvolvimento e a inclusão da sociedade no processo.

Palavras-chave: Convenção sobre diversidade biológica. Biodiversidade. Metas de Aichi. Áreas protegidas. Políticas públicas.

\footnotetext{
*** Pesquisadora sênior e professora do Programa Eicos/IP e do PPED/IE da UFRJ e do INCT/PPED/CNPq. Graduação em Biologia (UFRJ) e Psicologia (UERJ) Mestrado pela Universidade de Southampton (UK) e Doutorado em Ciências pela Universidade de São Paulo (1991). Pós-doutorado na EHESS e no MNHN da França. Lidera o Grupo de Pesquisa GAPIS/CNPq e o Observatório de Governança e Áreas Protegidas sediado na UFRJ. E-mail: marta.irving@mls.com.br
}

\section{Abstract}

Brazil has the richest biodiversity worldwide and was the first country to sign the Convention on Biological Diversity that established protected as one of the main instruments for biodiversity conservation areas. Within this context, the aim of the paper is to interpret, critically, advances, trends and 
challenges of public policies for protected in Brazil, in the light of the commitments made by the country under the Convention on Biological Diversity since its origin to the current areas Aichi Targets agreed at COP10 in Nagoya, Japan (2010) to contain the global loss of biodiversity. With this goal, the work focuses primarily on the analysis of the Aichi Target 11, relating to protected areas, compared to the obstacles and challenges of an emerging country. The product was developed based on literature and documentary research and also takes its inspiration from information obtained through direct participation in some of the Conferences of the Parties, recorded in a field notebook and systematic process for retrospective analysis. It can be concluded from the survey that Brazil has numerous instruments of public policy aimed at conserving biodiversity, particularly protected areas. However, at this juncture, as the central challenge remains the integration between public policies for biodiversity conservation and development and the inclusion of society in the process.

Keywords: Convention on biological diversity. Biodiversity. Aichi targets. Protected areas. Public policies.

\section{INTROdUZINDO A REFLEXÃo PROPOSTA: PARA CONTEXTUALIZAR A CDB}

Com um território continental que se estende por 8,5 milhões de $\mathrm{km}^{2}$, o Brasil é o quinto maior país do mundo e ocupa quase a metade de toda a América Latina, além de uma área marinha de mais de 4,5 milhões de km2. O país é considerado também como um dos populosos do planeta, com mais de 200 milhões de habitantes ${ }^{1}$, de origem e culturas variadas, segundo a sua própria história.

No que tange às riquezas naturais, o Brasil possui cinco importantes biomas continentais e o maior sistema fluvial do mundo, destacando-se no plano global, por abrigar a mais rica biota continental do planeta ${ }^{2}$. O território brasileiro abriga entre $15 \%$ e $20 \%$ de toda a biodiversidade mundial além do maior número de espécies endêmicas, a maior floresta tropical (a Amazônia) e dois dos dezenove botspots 3 mundiais (a Mata Atlântica e o Cerrado $)^{4}$ fato que confere ao país o primeiro lugar na lista dos países megadiversos ${ }^{5}$. Segundo as estimativas mais conservadoras, o Brasil abriga 13,2\% da biota mundial, o que significa cerca de 207.000 espécies conhecidas e 1,8 milhões de espécies estimadas incluindo aquelas ainda desconhecidas pela ciência ${ }^{6}$. Ou seja, no território nacional ocorrem importantes recursos de valor estratégico que são a fonte também de serviços ambientais essenciais para a manutenção da sociedade planetária.

Talvez por essa mesma razão, tenha sido o primeiro país a assinar a Convenção sobre Diversidade Biológica - CDB durante a Conferência das Organizações das Nações Unidas - ONU sobre Meio Ambiente e Desenvolvimento, a Rio92, evento de impacto global no debate ambiental, realizado no Rio de Janeiro, em 1992. A CDB foi o primeiro instrumento a abordar, especificamente, a tutela ${ }^{7}$ da biodiversidade no âmbito

1 Segundo o IBGE, em $1^{\circ}$ de julho de 2013 atingimos o número de 201.032.714 habitantes (RESOLUÇÃO N. 10, de 28 de AGOSTO de 2013- Diário Oficial da União de 29/08/2013).

2 BRANDON, K. et al. Conservação brasileira: desafios e oportunidades. Megadiversidade, Local, v. 1, n. 1, p. 7-13, jul. 2005.

3 Hotspot são biomas que abrigam um alto índice de espécies endêmicas com alto grau de ameaça pela atividade humana. O conceito de hotspot foi desenvolvido em 1988 pelo ecologista britânico Norman Myers e desde então apoiado por diversas organizações internacionais como a Conservação Internacional (MITTERMEIER, R. A. et al. Hotspots revisited: earth's biologically richest and most endangered terrestrial ecoregions. Mexico City: CEMEX, 2005).

4 DRUMMOND, G. M.; ANTONINI, Y. A contribuição da Fundação Biodiversitas para a implementação do art. $7^{\circ}$ da Convenção sobre Diversidade Biológica. In: BENSUSAN, Nurit (Ed.) et al. Biodiversidade: para comer, vestir ou passar no cabelo? São Paulo: Peirópolis, 2006.

5 Dos cerca de duzentos países atuais, apenas dezessete são considerados megadiversos, por conterem $70 \%$ da biodiversidade mundial. Entre esses, o Brasil está em primeiro lugar na lista, por abranger a maior diversidade biológica continental (GANEM, R. S. (Org.). Conservação da biodiversidade: legislação e políticas públicas. Brasília: Câmara dos Deputados, 2011. (Série memória e análise de leis)).

6 LEWINSOHN, T. (Coord.) Avaliação do estado do conbecimento da biodiversidade brasileira. Brasília: Ministério do Meio Ambiente, 2006. (Série Biodiversidade, 15).

7 Segundo Derani, (1997) a biodiversidade passou a integrar o mundo jurídico, como um objeto que necessita de sua tutela para 
internacional, estabelecendo princípios que orientam a proteção à diversidade biológica sua conservação e uso sustentável, com o compromisso de repartição justa e equitativa de seus benefícios ${ }^{8}$. Dessa forma, a CDB incorpora, em seus objetivos, um conjunto de valores inovadores para o desenvolvimento sustentável, segundo os anseios dos países reunidos naquela ocasião?.

Nesse contexto, não se pode negligenciar o cenário de crise ambiental global caracterizado por uma perda acelerada de espécies e ecossistemas. Essa crise agrava-se com a intensificação do desmatamento nos ecossistemas tropicais, nos quais se concentra a maior parte da biodiversidade global ${ }^{10}$. A perda da biodiversidade, em associação às mudanças climáticas, constitui um dos principais desafios a serem equacionados pelas sociedades contemporâneas, também para que seja possível atingir os Objetivos de Desenvolvimento do Milênio da $\mathrm{ONU}^{11}$, especialmente aqueles relacionados à redução da pobreza, à segurança alimentar e à conservação dos recursos hídricos ${ }^{12}$.

Dentre os mecanismos para a conservação da biodiversidade previstos na $\mathrm{CDB}$, visando garantir a manutenção e o uso sustentável da diversidade biológica para presentes e futuras gerações, destaca-se a modalidade de conservação in situ destinada à conservação da diversidade biológica em que ela ocorre naturalmente, definida pelo art. $2^{\circ}$ da Convenção como a

conservação de ecossistemas e habitats naturais e a manutenção e recuperação de populações viáveis de espécies em seus meios naturais e, no caso de espécies domesticadas ou cultivadas, nos meios em que tenham desenvolvido suas propriedades características ${ }^{13}$.

Dessa forma, o texto da CDB consagra, em seu artigo 8, o estabelecimento de um sistema de áreas protegidas como um mecanismo eficiente e tradicional para a conservação da biodiversidade nos diversos países signatários.

É importante enfatizar que as áreas protegidas constituem uma das principais estratégias para conter a perda da biodiversidade, representando um instrumento consagrado, em nível mundial, para a conservação da natureza ${ }^{14}$. Sistemas de áreas protegidas desempenham, em tese, papel vital no fornecimento de alimentos e água para a sociedade, no controle de doenças infecciosas, na regulação do clima e são fonte de inspiração cultural, espiritual e recreativa e também para a saúde física e menta ${ }^{15}$.

No Brasil, os dados sobre a cobertura em áreas protegidas é expressiva na sua porção continental e, na última década, o país foi o responsável pela criação de $74 \%$ das áreas criadas no planeta ${ }^{16}$. Nesse contexto, a área abrangida por unidades de conservação - UC no território brasileiro é de mais de 1,5 milhões de km²,

continuar existindo, pois do contrário, poderia ser explorada indiscriminadamente até o seu desaparecimento (DERANI, C. Direito ambiental econômico. São Paulo: Max Limonad, 1997).

8 FERREIRA, Gabriel Luís Bonora Vidrih; FERREIRA, Natália Bonora Vidrih; IURCONVITE, Adriano dos Santos. Biodiversidade e áreas protegidas: um enfoque constitucional. Ámbito Jurídico, Rio Grande, XIII, n. 74, março 2010. Disponível em: <http:// www.ambito-juridico.com.br/site/index.php?artigo_id=7362\&n_link=revista_artigos_leitura >. Acesso em: 03 mar. 2015.

9 BENSUSAN, Nurit (Ed.) et al. Biodiversidade: para comer, vestir ou passar no cabelo? São Paulo: Peirópolis, 2006.

10 GANEM, R. S. (Org.). Conservação da biodiversidade: legislação e políticas públicas. Brasília: Câmara dos Deputados, 2011. (Série memória e análise de leis).

11 Os oito Objetivos de Desenvolvimento do Milênio (ODM) da ONU compõem um plano acordado por todos os países do mundo e pelas principais instituições internacionais de desenvolvimento. Vão desde a redução para metade da pobreza extrema até deter a propagação da AIDS e fornecer educação primária universal, tudo até a data limite de 2015 <http://www.un.org/millenniumgoals $/>$.

12 LOPOUKHINE, N. et al. 2012. Protected areas: providing natural solutions to 21 st century challenges. Sapiens, [On line], v. 5, n.2, p. 116-131, August 2012. Available at: <http://sapiens.revues.org/1254> . Last access on: 08 apr. 2014.

13 BRASIL. Decreto Legislativo n. 2, de 3 de fevereiro de 1994. Decreto que aprova o texto da Convenção para o país. Disponível em: <http://legis.senado.gov.br/legislacao/ListaPublicacoes.action?id=139068>. Acesso em: 03 mar. 2015.

14 PIMM, S. L. et al. Can we defy nature's end? Science, London, v. 293, n. 5538, p. 2207-2208, sept. 2001.

15 STOLTON, S.; DUDLEY, N. (Ed.). Arguments for protected areas: multiple benefit for conservation and use. London: Earthscan, 2010.

16 JENKINS, C. N.; JOPPA, L. Expansion of the global terrestrial protected area system. Biological Conservation, London, v. 142 , p. 2166-2174, May, 2009. 
equivalente a 16,8\% do território continental brasileiro e 1,5\% do território marinho ${ }^{17}$. Esses dados tornam-se ainda mais expressivos quando comparados com outros países. Enquanto o Brasil tem aproximadamente $17 \%$ de seu território continental protegido por unidades de conservação (e 28,9\% incluindo-se nesse total também as terras indígenas), no mundo apenas $14,6 \%$ encontram-se sob proteção legal ${ }^{18}$.

Apesar do aumento significativo na criação de áreas protegidas no mundo (e também no Brasil), recentemente os países signatários da $\mathrm{CDB}$ reconheceram que não estão conseguindo conter as atuais taxas de perda da biodiversidade ${ }^{19}$. Dessa forma, durante a $10^{a}$ reunião das Partes da Convenção sobre Diversidade Biológica - COP10, realizada em Nagoya, Japão, 2010, foi aprovado o Plano Estratégico para a atual década, período inclusive designado pela ONU como a "década da biodiversidade 2011-2020"20. As 20 Metas de Aichi ${ }^{21}$ para 2020 são os elementos chave do Plano Estratégico para se conter a perda de biodiversidade. O Plano se constitui em uma orientação global sobre a biodiversidade, não só para as convenções relacionadas a ela relacionadas, mas para o todo o sistema das Nações Unidas ${ }^{22}$. Destaca-se, no conjunto de metas, para a análise deste artigo, a Meta 11 que incide especificamente sobre as áreas protegidas e passou a ser internalizada pelo governo brasileiro a partir de 2013. A meta 11 estabelece compromissos, visando à criação de novas áreas protegidas e também a sua efetividade, representatividade ecológica, governança e conectividade entre elas, conforme a transcrição a seguir:

Meta 11. Até 2020, que pelo menos 17\% das áreas terrestres e de águas continentais, e pelo menos $10 \%$ das áreas costeiras e marinhas, especialmente áreas de particular importância para a biodiversidade e para os serviços ecossistêmicos, terão sido conservados por meio de sistemas de áreas protegidas, geridas de maneira efetiva e equitativa, ecologicamente representativas e satisfatoriamente interligadas e por outras medidas espaciais de conservação, e integradas em paisagens terrestres e marinhas mais amplas.23

Mas, apesar da tentativa de avanço na cobertura de áreas protegidas, globalmente, ainda são inúmeros os desafios a serem enfrentados para que as boas intenções da COP10 sejam traduzidas em ações concretas na próxima década, sobretudo, em países megadiversos como o Brasil24. Dessa forma, o objetivo do artigo é interpretar, criticamente, os avanços, desafios e tendências das políticas públicas, referentes às áreas protegidas no Brasil à luz dos compromissos assumidos pelo país no âmbito da Convenção sobre Diversidade Biológica desde a sua origem até as atuais Metas de Aichi. A presente análise foi desenvolvida com base em pesquisa bibliográfica e documental e também tem como fonte as informações obtidas por meio da participação direta em algumas das Conferencias das Partes, registradas em cadernos de campo e sistematizadas para análise retrospectiva de processo em políticas públicas.

17 Fonte: Cadastro Nacional de Unidades de Conservação - CNUC/MMA, consultado em março/2014. <http://www.mma. gov.br/areas-protegidas/cadastro-nacional-de-ucs>.

18 BERTZKY, B. et al. Protected planet report 2012: tracking progress towards global targets for protected areas. IUCN: Gland, Switzerland; UNPE-WCMC: Cambridge, UK, 2012.

19 MINISTÉRIO DO MEIO AMBIENTE. Panorama da biodiversidade global 3. Brasília: Secretariado da Convenção Sobre Diversidade Biológica - SCDB, 2010.

20 <https://www.cbd.int/2011-2020/>

21 Aichi é o nome da província de Nagoya, cidade do Japão, onde foi realizada a COP10 da CDB.

22 O Sistema ONU trata-se do sistema formado por organizações autônomas que visam ao cumprimento dos objetivos da Organização das Nações Unidas (ONU), quais sejam, a manutenção da paz mundial; a mobilização da segurança internacional, quando necessário; o monitoramento dos direitos humanos e humanitários nos Estados membros; criação de políticas de desenvolvimento e cooperação entre os povos. São exemplos de programas e organizações que compõe o sistema ONU: a Organização Internacional do Trabalho (OIT), a Organização das Nações Unidas para Alimentação e Agricultura (FAO), a Organização Mundial da Saúde (OMS), o Fundo Monetário Internacional (FMI), o Fundo das Nações Unidas para a Infância (Unicef), o Programa das Nações Unidas para o Meio Ambiente (PNUMA) entre outras. (ver em: <http://www.onu.org.br/img/organograma.png>).

23 Ver todas as 20 Metas de Aichi no site da CDB: <http://www.cbd.int/sp/targets/>.

24 OLIVEIRA, Elizabeth; IRVING, Marta de Azevedo. Convenção sobre diversidade biológica pós Nagoya: desafios para a mídia em um país de megadiversidade. Razón y Palabra, México, v. 16, n. 75, feb./abr. 2011. Disponible en: <www.razonypalabra.org. $\mathrm{mx} / \mathrm{N} / \mathrm{N} 75 /$ varia_75/.../40_Oliveira_V75.pdf>. Acceso en: 03 mar. 2015. 


\section{A CONVENÇÃO SOBRE DIVERSIDADE BIOLÓGICA: ORIGEM E PRESSUPOSTOS}

A Convenção sobre Diversidade Biológica (CDB), popularmente conhecida como a Convenção da Biodiversidade, foi uma das convenções assinadas em 1992 durante a Conferência da ONU sobre Meio Ambiente e Desenvolvimento, a Rio-92. É considerada, em conjunto com as Convenções sobre Mudanças Climáticas e Desertificação, uma das três convenções do Rio que vem, desde então, influenciando a diplomacia global sobre a temática ambiental.

A CDB foi estabelecida em reconhecimento à taxa alarmante de perda de biodiversidade do mundo. Tendo em vista os riscos de tal processo, esse instrumento representa um quadro global de orientação para coordenar os esforços nacionais e facilitar a conservação da biodiversidade com inúmeras diretrizes e mecanismos para tal. No entanto, a aplicação da Convenção depende das ações desenvolvidas com este objetivo por parte de cada um dos países signatários, em escalas regional e nacional. Embora a Convenção possa ser considerada como um dispositivo jurídico baseado em uma abordagem “top-down”, ela representa importante instrumento para organizar e articular os esforços globais para alcançar a conservação da biodiversidade ${ }^{25}$.

A CDB representa, assim, compromisso histórico assumido pelas nações do mundo para conservar a diversidade biológica, a utilização sustentável dos recursos biológicos e, a repartição equitativa dos benefícios resultantes da utilização dos recursos genéticos ${ }^{26}$. Este foi o primeiro acordo global para abordar, de forma abrangente, todos os aspectos da diversidade de recursos genéticos, biológicos, espécies e ecossistemas ${ }^{27}$.

O texto da Convenção traz ainda avanço no conceito de diversidade biológica, quando em seu segundo artigo define a biodiversidade como a

variabilidade entre organismos vivos de todas as origens compreendendo, dentre outros, os ecossistemas terrestres, marinhos e outros ecossistemas aquáticos e os complexos ecológicos de que fazem parte; compreendendo ainda a diversidade dentro de espécies, entre espécies e de ecossistemas.

Com esse conceito amplo, que considera todas as formas de vida e seus conjuntos no planeta, a CDB consolidou nova forma de interpretar a natureza considerada decisiva para garantir os mecanismos para a manutenção da diversidade de vida, para a valorização das diferentes paisagens e para a interconexão entre esses diversos níveis de diversidade biológica ${ }^{28}$. Os reflexos dessa nova abordagem vêm influenciando políticas públicas em inúmeros países, entre os quais o Brasil desde então ${ }^{29}$.

A CDB é classificada, no sistema da ONU, como uma "Convenção Quadro", ou seja, uma convenção que não define regras obrigatórias a serem cumpridas e não impõe sanções aos países signatários que não cumprem as diretrizes acordadas. Constitui documento norteador para o cumprimento de objetivos comuns quanto à biodiversidade mundial, permitindo que cada país desenvolva suas estratégias com esse objetivo, a partir das suas próprias necessidades. Dessa forma, uma vez que a CDB considera a soberania como pressuposto $^{30}$, o sucesso para a sua implementação depende dos esforços realizados, individualmente, pelos países signatários que, por sua vez, estabelecem os seus próprios objetivos e metas a serem atingidos, visando proteger e utilizar seus recursos naturais de maneira sustentável ${ }^{31}$. A CDB institui, assim, o Estado como único

25 FIELDING, G. et al. What is the convention on biological diversity, and what is it trying to achieve? Journal of Conservation Biology 3065, London, v. 1, p. 1-7, [Online] 2009. Disponível em: http://myweb.dal.ca/bworm/Fielding_etal_CBD.pdf.

26 Esses são os três grandes objetivos: Conservação da Biodiversidade; Uso Sustentável dos componentes da biodiversidade; e, Repartição Justa e Equitativa dos Benefícios Advindos do Uso dos Recursos Genéticos (BRASIL. Decreto legislativo n. 2, de 3 de fevereiro de 1994. Disponível em: <http://legis.senado.gov.br/legislacao/ListaPublicacoes.action?id=139068>. Acesso em: 03 mar. 2015).

27 GLOWKA, L; BURHENNE-GUILMIN, F; SYNGE, H. A guide to the convention on biological diversity. 2. ed. IUCN: Gland; Cambridge, 1996.

28 BENSUSAN, Nurit (Ed.) et al. Biodiversidade: para comer, vestir ou passar no cabelo? São Paulo: Peirópolis, 2006.

29 Atualmente são 193 países signatários (ver site da convenção: <www.cbd.int>).

30 Os países signatários da CDB são chamados de Partes Contratantes.

31 FIELDING, G. et al. What is the convention on biological diversity, and what is it trying to achieve? Journal of Conservation Biology 3065, London, v. 1, p. 1-7, [Online] 2009. Disponível em: http://myweb.dal.ca/bworm/Fielding_etal_CBD.pdf. 
titular do acesso aos seus recursos, atribuindo papel complementar às comunidades tradicionais e locais e responsabilidades comuns, porém diferenciadas aos países signatários ${ }^{32}$.

Os países signatários da Convenção se reúnem a cada dois anos nas chamadas Conferências das Partes - COP. A COP constitui o órgão legítimo para a elaboração das leis especiais, que no caso da CDB são as denominadas "Decisões". Isso porque o artigo 23 da CDB estabelece que cabe à COP examinar e adotar protocolos e emendas à Convenção ou em seus anexos. Essas Decisões podem estabelecer protocolos, programas de trabalho ou ainda metas específicas a serem cumpridas pelos países signatários ${ }^{33}$. Atualmente, no âmbito da $\mathrm{CDB}$ dois Protocolos estão em vigor: Protocolo de Biossegurança (ou Protocolo de Cartagena, de 2000) e, o Protocolo de Acesso e Repartição de Benefícios (ou Protocolo de Nagoya, de 2010) 34 .

O texto da Convenção reconhece, pela primeira vez, no direito internacional que a conservação da biodiversidade constitui uma "preocupação comum da humanidade" 35 , mas nega a noção de ser a diversidade biológica um "patrimônio comum da humanidade", assegurando assim aos países signatários a soberania sobre sua própria biodiversidade e o controle do acesso aos recursos genéticos em seus respectivos territórios ${ }^{36}$.

Importante mencionar que, ao longo dos 22 anos de existência da CDB e a realização de 11 Conferências das Partes, foram aprovadas 332 Decisões para atender aos três objetivos da Convenção, quais sejam: conservação da biodiversidade, uso sustentável dos componentes da biodiversidade e repartição justa e equitativa dos benefícios advindos do uso dos recursos genéticos. Exatamente por essa razão e, em função da pluralidade de temas envolvidos, as decisões tomadas tendem a se dirigir às prioridades identificadas em cada momento ${ }^{37}$. Para melhor contextualização do processo de implementação da CDB, o Quadro 1, a seguir, sintetiza os principais atos e reuniões referentes à Convenção no período de 1992 a 2012.

Quadro 1 - Marcos institucionais e eventos de referência no processo da implementação da CDB no plano global e nacional (entre 1992 a 2012) (continua)

\begin{tabular}{|c|c|c|c|}
\hline $\begin{array}{c}\text { Marco } \\
\text { institucional/ } \\
\text { Evento } \\
\end{array}$ & Local & $\begin{array}{c}\text { Data/ } \\
\text { Ano }\end{array}$ & Descrição \\
\hline Rio 92 & $\begin{array}{l}\text { Rio de } \\
\text { janeiro, } \\
\text { Brasil }\end{array}$ & 1992 & $\begin{array}{l}2^{\text {a }} \text { Conferência das Nações Unidas sobre Meio Ambiente } \\
\text { e Desenvolvimento; O termo biodiversidade foi o cen- } \\
\text { tro das discussões. Assinada a Convenção de Diversidade } \\
\text { Biológica-CDB. }\end{array}$ \\
\hline $\begin{array}{c}\text { Decreto } \\
\text { Legislativo } \mathrm{n}^{\circ} 2\end{array}$ & Brasil & $3 / 2 / 1994$ & Aprova o texto da Convenção para o país. \\
\hline
\end{tabular}

32 Segundo Machado, os instrumentos internacionais não procuram desfazer o princípio da soberania, mas sim criar novos mecanismos de gestão e responsabilidade em conjunto para melhor gestão e proteção ambiental, quando os Estados individualmente não podem proteger o meio ambiente. Segundo o autor um exemplo desse processo de descentralização ambiental é a CDB (MACHADO, F. P. M. Soberania e meio ambiente: a adequação do direito internacional às novas necessidades de gestão ambiental e os mecanismos da ONU para resolução de conflitos. PRISMAS: Dir., Pol. Pub. e Mundial, Brasília, v.4, n, 1, p. 123-150, jan.jul. 2007).

33 As decisões das COPs são orientadas por recomendações de um Órgão Subsidiário de Assessoramento Científico, Técnico e Tecnológico da CDB (com a sigla - SBSTTA do nome em inglês Subsidiary Body on Scientific Technical and Technological Advice).

34 TEN KATE, K. Science and the convention on biological diversity. Science, London, v. 295, n. 5564, p. 2371-2372, mar. 2002. 35 BRASIL. Decreto legislativo n. 2, de 3 de fevereiro de 1994. Disponível em: < http://legis.senado.gov.br/legislacao/ListaPublicacoes. action?id=139068>. Acesso em: 03 mar. 2015.

36 HEYWOOD, V. H. ¿Cuál es el futuro de la biodiversidad? Ambienta, Madrid, n. 101, p. 20-40, dez. 2012.

37 Por exemplo, pode-se destacar que a COP2 foi um marco para a biodiversidade marinha. A COP7, por sua vez, foi marcada pela aprovação do Programa de Trabalho de Áreas Protegidas (Program of Work of Protected Areas - PoWPA), ver Quadro 1. 


\begin{tabular}{|c|c|c|c|}
\hline $\begin{array}{c}\text { Marco } \\
\text { institucional/ } \\
\text { Evento }\end{array}$ & Local & $\begin{array}{c}\text { Data/ } \\
\text { Ano }\end{array}$ & Descrição \\
\hline COP1 & $\begin{array}{l}\text { Nassau, } \\
\text { Bahamas }\end{array}$ & 1994 & $\begin{array}{l}\text { Primeira COP na qual foram tomadas decisões de ordem } \\
\text { mais burocrática, visando ao funcionamento da Con- } \\
\text { venção como: definição do quadro geral para a imple- } \\
\text { mentação da Convenção; estabelecimento do mecanismo } \\
\text { de "Clearing House" (CHM)1, do SBSTTA, e a designação } \\
\text { do Global Environmental Facility - GEF2 como mecanismo } \\
\text { financeiro interino. }\end{array}$ \\
\hline COP2 & $\begin{array}{l}\text { Jakarta, } \\
\text { Indonésia }\end{array}$ & 1995 & $\begin{array}{l}\text { Reunião decisiva sobre biodiversidade costeira e marinha, } \\
\text { pois foi aprovada a primeira decisão estabelecendo o pro- } \\
\text { grama de trabalho dirigido ao tema (o Mandato de Jacar- } \\
\text { ta). Além disso, foi estabelecido um Grupo de Trabalho } \\
\text { para a elaboração de um protocolo sobre biossegurança. }\end{array}$ \\
\hline COP3 & $\begin{array}{l}\text { Buenos } \\
\text { Aires, } \\
\text { Argentina }\end{array}$ & 1996 & $\begin{array}{l}\text { Reunião na qual o ponto mais significativo foi a adoção de } \\
\text { um Memorando de Entendimento para o GEF, tornan- } \\
\text { do esse mecanismo o fundo mais importante de financia- } \\
\text { mento aos países em desenvolvimento3. }\end{array}$ \\
\hline Decreto $\mathrm{n}^{\circ} 2.519$ & Brasil & $16 / 3 / 1998$ & Promulga a CDB no Brasil. \\
\hline COP4 & $\begin{array}{l}\text { Bratislava, } \\
\text { Eslováquia }\end{array}$ & 1998 & $\begin{array}{l}\text { COP marcada pelo estabelecimento do Grupo de Tra- } \\
\text { balho sobre Conhecimento Tradicional (Artigo 8j) e pela } \\
\text { criação de um painel de especialistas em ABS4 (Acesso e } \\
\text { Repartição de Benefício). Adotou-se também um progra- } \\
\text { ma de trabalho sobre biodiversidade florestal e, a Iniciati- } \\
\text { va Global de Taxonomia. }\end{array}$ \\
\hline EXCOP1 & $\begin{array}{l}\text { Cartagena, } \\
\text { Colômbia } \\
\text { Montreal, } \\
\text { Canadá }\end{array}$ & 1999 & $\begin{array}{l}\text { Primeira Reunião Extraordinária realizada da COP } \\
\text { (EXCOP) que não chegou a um consenso sobre as nego- } \\
\text { ciações relacionadas a um protocolo de biossegurança e, a } \\
\text { reunião de Cartagena foi suspensa. A EXCOP1 foi reto- } \\
\text { mada em janeiro de 2000, em Montreal, onde finalmente } \\
\text { foi adotado o Protocolo de Cartagena sobre Biossegurança } \\
\text { e foi também estabelecido o Comitê Intergovernamental } \\
\text { para o Protocolo, visando realizar os preparativos para as } \\
\text { próximas reuniões do Protocolo que começaram a ser de- } \\
\text { signadas como Meetings of the Parties - MOPs5. O Protoco- } \\
\text { lo trata da transferência, manipulação e uso de organismos } \\
\text { vivos modificados que possam ter um efeito adverso sobre } \\
\text { a biodiversidade, tendo em conta a saúde humana, com um } \\
\text { enfoque específico nas questões transfronteiriças. }\end{array}$ \\
\hline COP5 & $\begin{array}{l}\text { Nairobi, } \\
\text { Quênia }\end{array}$ & 2000 & $\begin{array}{l}\text { COP na qual foram adotados os programas de trabalho } \\
\text { sobre: terras áridas e subúmidas; medidas de incentivo; } \\
\text { artigo } 8 \text { j e sobre biodiversidade agrícola. Foi ainda endos- } \\
\text { sada a descrição e orientação operacional sobre a aborda- } \\
\text { gem ecossistêmica, e estabelecido um Grupo de Trabalho } \\
\text { sobre ABS. }\end{array}$ \\
\hline
\end{tabular}




\begin{tabular}{|c|c|c|c|}
\hline $\begin{array}{c}\text { Marco } \\
\text { institucional/ } \\
\text { Evento }\end{array}$ & Local & $\begin{array}{c}\text { Data/ } \\
\text { Ano }\end{array}$ & Descrição \\
\hline COP6 & $\begin{array}{l}\text { Haia, } \\
\text { Holanda }\end{array}$ & 2002 & $\begin{array}{l}\text { COP na qual foi adotado o primeiro conjunto de metas } \\
\text { para o período 2002-2010. Um plano estratégico foi cria- } \\
\text { do para orientar a implementação da Convenção, em nível } \\
\text { nacional, regional e global com o propósito de interrom- } \\
\text { per a perda de biodiversidade e assegurar a continuidade } \\
\text { de seus benefícios e sua repartição equitativa. }\end{array}$ \\
\hline COP7 & $\begin{array}{l}\text { Kuala } \\
\text { Lumpur, } \\
\text { Malásia }\end{array}$ & 2004 & $\begin{array}{l}\text { A COP mais significativa sobre o tema das Áreas Prote- } \\
\text { gidas, quando foi adotado o Programa de Trabalho sobre } \\
\text { o tema (Program of Work on Protected Areas - PoWPA) que } \\
\text { pautou todos os futuros compromissos e ações sobre áre- } \\
\text { as protegidas em nível global. Além disso, foram também } \\
\text { aprovados os programas de trabalho sobre biodiversidade } \\
\text { de montanhas, e sobre transferência de tecnologia e coo- } \\
\text { peração internacional. }\end{array}$ \\
\hline COP8 & $\begin{array}{c}\text { Curitiba, } \\
\text { Brasil }\end{array}$ & 2006 & $\begin{array}{l}\text { COP na qual foi adotado um programa de trabalho so- } \\
\text { bre a biodiversidade insular. Foram também iniciadas as } \\
\text { discussões sobre áreas protegidas além das jurisdições } \\
\text { nacionais. O Grupo de Trabalho sobre ABS foi formal- } \\
\text { mente encarregado de concluir o seu trabalho, no que diz } \\
\text { respeito a adoção de um regime internacional de ABS, no } \\
\text { máximo até a COP10. Essa COP foi marcada pela origi- } \\
\text { nalidade do governo brasileiro em realizar feiras paralelas } \\
\text { com stands institucionais sobre biodiversidade e um núme- } \\
\text { ro elevado de eventos paralelos. Em um desses eventos } \\
\text { paralelos foi organizada uma reunião extraordinária do } \\
\text { CONAMA6 que aprovou o Decreto do Plano Estratégico } \\
\text { Nacional de Áreas Protegidas - PNAP. }\end{array}$ \\
\hline COP9 & $\begin{array}{c}\text { Bonn, } \\
\text { Alemanha }\end{array}$ & 2008 & $\begin{array}{l}\text { COP que teve como resultado a aprovação da Estratégia } \\
\text { de Mobilização de Recursos, os critérios científicos e } \\
\text { orientação para as áreas marinhas que necessitam de pro- } \\
\text { teção e um roteiro para a negociação do regime internacio- } \\
\text { nal de ABS. Foi também formado um grupo ad hoc sobre } \\
\text { biodiversidade e mudanças climáticas. Para as áreas pro- } \\
\text { tegidas, destaca-se a aprovação da Iniciativa Lifeweb que } \\
\text { vem a ser uma plataforma de captação de doadores para a } \\
\text { implementação dos respectivos planos de áreas protegidas } \\
\text { (PowPAs) nos países em desenvolvimento7. }\end{array}$ \\
\hline
\end{tabular}




\begin{tabular}{|c|c|c|l|}
\hline $\begin{array}{c}\text { Marco } \\
\text { institucional/ } \\
\text { Evento }\end{array}$ & Local & $\begin{array}{c}\text { Data/ } \\
\text { Ano }\end{array}$ & \multicolumn{1}{|c|}{ Descrição } \\
\hline \multirow{1}{*}{ COP10 } & Nagoya, & $\begin{array}{l}\text { Uma das COPs mais tensas no debate da CDB. Os países } \\
\text { que apoiavam o estabelecimento do Protocolo sobre ABS } \\
\text { pressionaram, até o último momento, sua adoção. Se isso } \\
\text { não acontecesse não iriam aprovar nenhuma das demais } \\
\text { decisões, inclusive o novo Plano Estratégico da CDB. } \\
\text { Dessa forma, a COP 10 foi marcada pela adoção do Pro- } \\
\text { tocolo de Nagoya sobre Acesso a Recursos Genéticos e } \\
\text { Repartição Justa e Equitativa dos Benefícios decorrentes } \\
\text { da sua utilização, que estabelece regras e procedimentos } \\
\text { para a implementação do terceiro objetivo da Convenção. } \\
\text { Destacam-se as seguintes aprovações: o Plano Estratégi- } \\
\text { co da CDB para o período 2011-2020, nesta incluídas as } \\
\text { metas de Aichi para conter a perda de biodiversidade; a } \\
\text { aprovação da necessidade de descrição das Ecological and } \\
\text { Biological Sensitive Marine Areas - EBS AS; e, uma decisão } \\
\text { sobre as atividades e indicadores para a implementação } \\
\text { da Estratégia de Mobilização de Recursos, visando atingir } \\
\text { as metas de Aichi. Por isso essa foi a COP considerada a } \\
\text { mais bem sucedida na história das COPs. Além disso, foi } \\
\text { afirmado o papel da CBD nos mecanismos de redução } \\
\text { das emissões de desmatamento e degradação florestal nos } \\
\text { países em desenvolvimento (REDD+). Foram estabele- } \\
\text { cidos os passos para ampliar a cooperação entre as Con- } \\
\text { venções do Rio, visando anteceder a Cúpula Rio +20. }\end{array}$ \\
\hline
\end{tabular}




\begin{tabular}{|c|c|c|c|}
\hline $\begin{array}{c}\text { Marco } \\
\text { institucional/ } \\
\text { Evento } \\
\end{array}$ & Local & $\begin{array}{c}\text { Data/ } \\
\text { Ano }\end{array}$ & Descrição \\
\hline COP11 & $\begin{array}{c}\text { Hyderabad } \\
\text { Índia }\end{array}$ & 2012 & $\begin{array}{l}\text { A COP11 aprovou } 33 \text { decisões sobre questões estratégi- } \\
\text { cas, substantivas, administrativas, financeiras e orça- } \\
\text { mentárias. Entre outras questões, o encontro abordou a } \\
\text { situação do Protocolo de Nagoya, a implementação do } \\
\text { Plano Estratégico 2011-2020, os avanços na consecução } \\
\text { das metas de Aichi e, a implementação da Estratégia de } \\
\text { Mobilização de Recursos, essa última a mais polêmica. A } \\
\text { estratégia estabelece uma meta intermediária de dobrar os } \\
\text { fluxos de recursos financeiros internacionais, relaciona- } \\
\text { dos à biodiversidade, para os países em desenvolvimento, } \\
\text { até } 2015 \text {, e, pelo menos manter esse nível, até } 2020 \text {. A } \\
\text { estratégia é acoplada às metas de Aichi, visando melho- } \\
\text { rar a robustez das informações de base - relatório pre- } \\
\text { liminar para o monitoramento sobre a mobilização de } \\
\text { recursos. Dessa forma, foram antecipados itens para a } \\
\text { pauta da COP12, a ser realizada em outubro de } 2014 \text { em } \\
\text { Pyeongchang, Coreia do Sul, para analisar os avanços de } \\
\text { negociações com vista à aprovação da meta final para a } \\
\text { mobilização de recursos. Foram ainda adotadas decisões } \\
\text { importantes sobre o artigo 8j e adotados os resultados dos } \\
\text { primeiros workshops para a descrição das EBSAS, den- } \\
\text { tre eles o workshop regional sediado pelo Brasil para a } \\
\text { região do Caribe e meio atlântico sul8. Destaca-se nessa } \\
\text { COP a realização de vários eventos paralelos entre eles o } \\
\text { Colloquium sobre as ICCAs, comentado a seguir, uma feira } \\
\text { sobre experiências e melhores práticas em comunicação, } \\
\text { educação e conscientização pública (CEPA), o Pavilion das } \\
\text { Convenções do Rio e a Cúpula sobre biodiversidade e ci- } \\
\text { dades. }\end{array}$ \\
\hline
\end{tabular}

Essa síntese do histórico de implementação da CDB ilustra a complexidade envolvida em sua negociação com rebatimentos evidentes em sua estrutura.

Sendo assim, para atingir os seus objetivos, a CDB está estruturada em sete Programas Temáticos ${ }^{38}$ além de envolver 18 temas transversais. O processo é coordenado por um Secretariado, composto por um Secretário Executivo e uma equipe de técnicos especialistas nos diversos temas associados às questões abordadas nesse $\mathrm{b}$ dispositivo jurídico ${ }^{39}$. E, devido à importância e transversalidade de alguns temas e, de acordo com as demandas identificadas em cada ocasião, o Secretariado pode estabelecer, Grupos de Trabalho Permanentes como no caso de Áreas Protegidas ${ }^{40}$.

38 Programas Temáticos da CDB: Biodiversidade Marinha e Costeira; Biodiversidade na Agricultura; Biodiversidade de terras subúmidas e secas; Biodiversidade de Florestas; Biodiversidade de águas interiores; Biodiversidade de Ilhas e Biodiversidade de Montanhas e 18 Temas Transversais, como: Áreas Protegidas; Espécies Invasoras; Iniciativa Global de Taxonomia; BD e Mudanças Climáticas; Metas de Aichi; Abordagem Ecossistêmica; Avaliação de Impactos; Indicadores, entre outros <www.cbd.int>.

39 Ver mais detalhes sobre o Secretariado no site da Convenção: <www.cbd.int>.

40 Outros exemplos de grupos permanentes criados pelo Secretariado: Artigo $8 j$ (populações indígenas e locais); Revisão da implementação da Convenção e um Comitê Intergovernamental para o Protocolo de Nagoya. 


\section{3. Áreas protegidas Na CDB}

O termo "área protegida" é definido no Artigo $2^{\circ}$ da Convenção como "uma área geograficamente definida, que é designada ou regulamentada e gerida para alcançar objetivos específicos de conservação". O Artigo $8^{\circ}$ da Convenção estabelece, nesse sentido, também as diretrizes para a conservação in situ, incentivando os países signatários $\mathrm{a}^{41}$ :

a. Estabelecer um sistema de áreas protegidas ou áreas onde medidas especiais precisem ser tomadas para conservar a diversidade biológica;

b. Desenvolver, se necessário, diretrizes para a seleção, estabelecimento e administração de áreas protegidas ou áreas onde medidas especiais precisem ser tomadas para conservar a diversidade biológica;

c. Regulamentar ou administrar recursos biológicos importantes para a conservação da diversidade biológica, dentro ou fora de áreas protegidas, a fim de assegurar sua conservação e utilização sustentável;

d. Promover a proteção de ecossistemas, habitats naturais e manutenção de populações viáveis de espécies em seu meio natural;

e. Promover o desenvolvimento sustentável e ambientalmente sadio em áreas adjacentes às áreas protegidas a fim de reforçar a proteção dessas áreas;

f. Recuperar e restaurar ecossistemas degradados e promover a recuperação de espécies ameaçadas, mediante, entre outros meios, a elaboração e implementação de planos e outras estratégias de gestão;

g. Estabelecer ou manter meios para regulamentar, administrar ou controlar os riscos associados à utilização e liberação de organismos vivos modificados resultantes da biotecnologia que provavelmente provoquem impacto ambientar negativo que possa afetar a conservação e a utilização sustentável da diversidade biológica, levando também em conta os riscos para a saúde humana;

h. Impedir que se introduzam, controlar ou erradicar espécies exóticas que ameacem os ecossistemas, habitats ou espécies;

i. Procurar proporcionar as condições necessárias para compatibilizar as utilizações atuais com a conservação da diversidade biológica e a utilizado sustentável de seus componentes;

j. Em conformidade com sua legislação nacional, respeitar, preservar e manter o conhecimento, inovações e práticas das comunidades locais e populações indígenas com estilo de vida tradicionais relevantes à conservação e à utilização sustentável da diversidade biológica e incentivar sua mais ampla aplicação com a aprovação e a participação desse conhecimento, inovações e práticas; e encorajar a repartição equitativa dos beneficias oriundos da utilização desse conhecimento, inovações e práticas;

k. Elaborar ou manter em vigor a legislação necessária e/ou outras disposições regulamentares para a proteção de espécies e populações ameaçadas;

1. Quando se verifique um sensível efeito negativo à diversidade biológica, em conformidade com o Artigo 7, regulamentar ou administrar os processos e as categorias de atividades em causa; e

m. Cooperar com o aporte de apoio financeiro e de outra natureza para a conservação in-situ a que se referem as alíneas (a) a (1) acima, particularmente aos países em desenvolvimento.

41 BRASIL. Decreto legislativo n. 2, de 3 de fevereiro de 1994. Disponível em: < http://legis.senado.gov.br/legislacao/ListaPublicacoes. action?id=139068>. Acesso em: 03 mar. 2015. 
A Convenção reconhece, assim, as áreas protegidas, como um dos principais instrumentos para a conservação da biodiversidade e, a maioria dos Programas de Trabalho previstos para a sua implementação inclui diretrizes e interfaces com a temática das áreas protegidas, segundo resumido no Quadro 2 a seguir:

Quadro 2: Programas da CDB com interface com a temática de áreas protegidas ${ }^{42}$

\begin{tabular}{|l|l|}
\hline \multicolumn{1}{|c|}{ Programa Temático da CDB } & \multicolumn{1}{c|}{ Interface com o tema áreas protegidas } \\
\hline $\begin{array}{l}\text { Programa de Trabalho sobre Bio- } \\
\text { diversidade Marinha e Costeira }\end{array}$ & $\begin{array}{l}\text { As áreas protegidas costeiras e marinhas são descritas como ferra- } \\
\text { menta essencial para a conservação e uso sustentável da biodiversi- } \\
\text { dade marinha e costeira. }\end{array}$ \\
\hline $\begin{array}{l}\text { Programa de Trabalho sobre } \\
\text { Ecossistemas de água doce }\end{array}$ & $\begin{array}{l}\text { Se reafirma a importância das áreas protegidas para a manutenção } \\
\text { dos ecossistemas de águas interiores, no âmbito de uma gestão inte- } \\
\text { grada por bacia hidrográfica. }\end{array}$ \\
\hline $\begin{array}{l}\text { Programa de Trabalho sobre Bio- } \\
\text { diversidade Florestal }\end{array}$ & $\begin{array}{l}\text { Contém uma série de diretrizes relacionadas às áreas protegidas, in- } \\
\text { cluindo o estabelecimento de novas florestas protegidas para con- } \\
\text { trolar o desmatamento e evitar as emissões de gases de efeito estufa. }\end{array}$ \\
\hline $\begin{array}{l}\text { Programa de Trabalho sobre } \\
\text { Conhecimento Tradicional }\end{array}$ & $\begin{array}{l}\text { Refere-se ao Artigo 8j da Convenção, inclui um componente rela- } \\
\text { cionado com a gestão de áreas protegidas por povos indígenas e lo- } \\
\text { cais. Na COP7, uma ênfase especial é dirigida a respeito dos direitos } \\
\text { dessas populações ao se estabelecer novas áreas protegidas. }\end{array}$ \\
\hline $\begin{array}{l}\text { Programa de Trabalho sobre Turi- } \\
\text { smo e Biodiversidade }\end{array}$ & $\begin{array}{l}\text { Inclui orientações sobre como incorporar o uso sustentável e } \\
\text { estratégias de ações para o turismo, no interior e no entorno de áreas } \\
\text { protegidas. }\end{array}$ \\
\hline $\begin{array}{l}\text { Estratégia Global para a Conser- } \\
\text { vação de Plantas }\end{array}$ & $\begin{array}{l}\text { Tem como foco central a necessidade de se estabelecer pelo menos } \\
10 \% \text { de cada uma das regiões ecológicas do mundo efetivamente } \\
\text { conservada, o que implica no aumento da representação dos dife- } \\
\text { rentes regiões ecológicas em áreas protegidas, além de se buscar o } \\
\text { aumento na eficácia dessas áreas. }\end{array}$ \\
\hline
\end{tabular}

No processo de implementação da CDB, no entanto, a reunião mais importante para o tema Áreas Protegidas foi, sem dúvida, a COP7 realizada em Kuala Lumpur, Malásia, em 2004 como anteriormente descrito no Quadro 1. Nesta Conferência foi adotado o Programa de Trabalho sobre Áreas Protegidas (PoWPA) com o objetivo geral de "estabelecer e manter, até 2010, para áreas terrestres e até 2012 para áreas marinhas sistemas abrangentes, geridos de forma eficaz e ecologicamente representativos de áreas protegidas", visando reduzir, significativamente, a taxa de perda de biodiversidade global ${ }^{43}$. Essa medida foi acordada a partir do reconhecimento de erosão progressiva da biodiversidade, com a consequência de extinção de espécies, fragmentação de habitats, perdas irreversíveis de serviços ecossistêmicos, entre outros problemas, conforme discutido por diversos autores ${ }^{44}$ e nos inúmeros debates realizados durante o Congresso Mundial de Parques promovido pela IUCN ${ }^{45} \mathrm{em} 2003^{46}$.

A estratégia de implementação do PoWPA pelos países signatários buscou contribuir para os três objetivos centrais da Convenção e para o cumprimento do $1^{\circ}$ Plano Estratégico com metas para a biodiversidade

42 Ver site da CDB: < www.cbd.int>.

43 COAD, L. et al. Progress on the convention on biological diversity's 2010 and 2012 targets for protected area coverage. In: LOOKING TO THE FUTURE OF THE CBD PROGRAMME OF WORK ON PROTECTED AREAS, 2009, Jeju Island. Proceedings... Republic of Korea: Jeju Island, 2009. p. 14-17.

44 BUTCHART, Stuart. H. M. et. al. Global biodiversity: indicators of recent declines. Science, London, v. 328, n.5982, p. $1164-$ 1168, may 2010.

45 IUCN: The World Conservation Union/União Mundial para a Conservação, antes chamada International Union for Conservation of Nature é uma Organização não Governamental que congrega várias instituições públicas e privadas relacionadas com a conservação da natureza no mundo. É interlocutora privilegiada do Programa das Nações Unidas para o Meio Ambiente - PNUMA e da CDB. Promove importantes ações educativas, normativas e de controle no âmbito da conservação da natureza em geral, e da conservação dos ecossistemas e das espécies, em particular <http://www.iucn.org/>.

46 PIMM, S. L. et al. Can we defy nature's end? Science, London, v. 293, n. 5538, p. 2207-2208, sept. 2001. 
para o período de $2002-2010^{47}$, para a redução da pobreza e, com as metas de desenvolvimento sustentável dos Objetivos de Desenvolvimento do Milênio ${ }^{48}$.

Paralelamente às discussões sobre o Programa de Áreas Protegidas, no processo, foram progressivamente intensificados também os debates no Grupo de Trabalho sobre o Artigo 8j relativo às questões dos povos e comunidades tradicionais ${ }^{49} \mathrm{e}$, o reconhecimento da importância dessas populações para a conservação da biodiversidade. As áreas destinadas aos povos e comunidades tradicionais, ou aquelas por eles geridas, passaram então a ser designadas como ICCAS (Indigenous Peoples and Community Conserved Territories and Areas). Apesar dessas áreas já terem sido reconhecidas no Programa de Trabalho sobre Áreas Protegidas (PoWPA), muitos países não as consideravam em suas estatísticas oficiais, o que implicava em estimativas subdimensionadas com relação ao território protegido, em nível global. Tal fato interferiu nas negociações das Metas de Aichi, resultando em acordos de percentuais a serem alcançados inferiores ao desejado para a Meta $11^{50}$. Em razão disso, o Secretariado da CDB passou a investir na disseminação do conceito das ICCAs, com a publicação de documentos e guias orientadores para a inclusão dessas áreas nos respectivos sistemas nacionais e realizou, com esse objetivo um Colloquium sobre o tema durante a COP11, em $2012^{51}$.

Em rebatimento ao debate global, no Brasil a cronologia de implementação da CDB vem se afirmando, progressivamente, em ações de políticas públicas quanto ao tema das áreas protegidas. Sendo assim, a importância da Convenção, no país, vem sendo internalizada, considerando-se desde o financiamento de parte do Sistema Nacional de Unidades de Conservação ${ }^{52}$, até o reconhecimento atribuído às populações tradicionais e indígenas nessas áreas.

\section{Políticas públicas para as Áreas protegidas no Brasil: em qUe medida os COMPROMISSOS DA CDB VEM SENDO INTERNALIZADOS?}

Para avançar no debate proposto, é importante mencionar que, nas últimas três décadas, importantes avanços têm ocorrido, no país, para o aprimoramento da legislação ambiental e para a institucionalização da questão ecológica ${ }^{53}$. Além de ter sido o primeiro país signatário da Convenção, em 1992, o Brasil tem tido um papel de destaque nas negociações envolvidas no campo diplomático nesse tema. O primeiro avanço, nesse sentido, foi o próprio Decreto que aprova o texto da Convenção para o país ${ }^{54}$. Nessa cronologia, outros diplomas legais tendo a CDB como pano de fundo foram também estabelecidos. Esse é o caso da Lei

47 Ver no Quadro 1 a descrição sobre a COP6, 2002.

48 O PoWPA continha metas com prazos específicos organizados principalmente em torno de ações de nível nacional exatamente para incentivar os países a estabelecerem seus respectivos programas nacionais.

49 Ver no Quadro 1 a descrição sobre a COP4, 1998.

50 LOPOUKHINE, N.; DIAS, B. F. S. What does target 11 really mean? Parks, Gland, Switzerland, v. 18, n. 1, p. 5-8, sept 2012. 51 REPORT of the Colloquium on the Role of ICCAs in Achieving the Aichi Targets. Hyderabad, India, 13 oct. 2012. Available at: <http://www.cbd.int/doc/pa/icca-day-report-en.pdf>. Last access on: 03 mar. 2015; KOTHARI, A. et al. Recognising and supporting territories and areas conserved by indigenous peoples and local communities: global overview and national case studies. Montreal, Canada: Secretariat of the Convention on Biological Diversity, 2012. (CBD Technical Series, 64).

52 O Brasil já teve mais de 54 projetos aprovados para o âmbito nacional sendo que desses, o Ministério do Meio Ambiente executa hoje quatro projetos aprovados pelo GEF, específicos para o fortalecimento do sistema nacional de unidades de conservação. Destaca-se o Projeto Áreas Protegidas da Amazônia - ARPA que teve seu início em 2002 prevendo uma duração de 13 anos e execução em 3 fases. É considerado pelo próprio GEF como um dos maiores programas de conservação de florestas tropicais desenvolvidos no mundo. O ARPA já recebeu do GEF US\$30 milhões. < http://www.thegef.org/gef/project_list>.

53 Segundo Irving, 2010, "nos últimos anos, a partir da Politica Nacional de Meio Ambiente (BRASIL, 1981) e da Constituição Federal de 1988 (BRASIL, 1988), a democratização da gestão de patrimônio natural e o protagonismo social nas ações governamentais de proteção da natureza passaram a se constituir em compromisso central em politicas publicas, ainda que no primeiro momento apenas no plano do discurso politico.” (IRVING, M. A. Áreas protegidas e inclusão social: uma equação possível em políticas públicas de proteção da natureza no Brasil? Sinais Sociais, Rio de Janeiro, v. 4, n. 12, p. 122-147, jan/abril 2010.

54 A CDB foi aprovada pelo Decreto Legislativo $n^{\circ} 2$, de 3 de fevereiro de 1994, e promulgada pelo Decreto $\mathrm{n}^{\circ} 2.519$, de 16 de março de 1998. 
que institui o Sistema Nacional de Unidades de Conservação da Natureza - o SNUC ${ }^{55}$. Embora este não tenha sido originado diretamente da CDB, (uma vez que as primeiras versões são anteriores a ela), durante a sua tramitação no Congresso Nacional, que durou aproximadamente 12 anos, foram incorporadas ao texto desse dispositivo legal algumas das diretrizes da Convenção ${ }^{56}$. E esse Sistema passou também a representar, desde então, o principal instrumento dirigido à conservação da biodiversidade no Brasil.

Importante também mencionar no processo que, em 2006, dois anos após a COP7 quando foi aprovado no âmbito da CDB o PoWPA, o governo brasileiro estabeleceu o Plano Nacional Estratégico sobre Áreas Protegidas (PNAP) ${ }^{57}$ como forma de internalizar os compromissos do Plano de Trabalho da CDB. O PNAP foi reconhecido pelo Decreto 5.758/2006 e constitui, na atualidade, uma das principais políticas públicas para as áreas protegidas, abrangendo além das unidades de conservação (SNUC) ${ }^{58}$, as Terras Indígenas e as Terras de Quilombos, como será discutido posteriormente na análise deste artigo.

Mas, para uma melhor contextualização da CDB em seus reflexos nacionais, o Quadro 3, a seguir, sintetiza as principais políticas públicas no Brasil, com interfaces com a temática de áreas protegidas.

55 Lei 9.985 de 18 de julho de 2000 e o Decreto que regulamenta a Lei - Decreto 4.340 de 22 de agosto de 2002.

56 MERCADANTE, M. Uma década de debate e negociação: a história da elaboração da lei do SNUC. In: HERMAN, A. B. (Coord.). Direito ambiental das áreas protegidas. Rio de Janeiro: Forense Universitária, 2001. p. 190-231.

57 BRASIL. Decreto n. 5.758, de 13 de abril de 2006. Plano Estratégico Nacional de Áreas Protegidas. Disponível em: <http://www. planalto.gov.br/ccivil_03/_Ato2004-2006/2006/Decreto/D5758.htm>. Acesso em: 03 mar. 2015.

58 Segundo o SNUC constituem-se as unidades de conservação como: "espaços territoriais e seus recursos ambientais, incluindo as águas jurisdicionais, com características naturais relevantes, legalmente instituídos pelo Poder Público, com objetivos de conservação e limites definidos, sob regime especial de administração, ao qual se aplicam garantias adequadas de proteção da lei". No SNUC as UCs se dividem ainda em dois grupos distintos de manejo: UC de proteção integral e UC de uso sustentável. (BRASIL. Lei n. 9.985, de 18 de julho de 2000. Disponível em: <http://www.planalto.gov.br/ccivil_03/leis/19985.htm>. Acesso em: 03 mar. 2015. 
Quadro 3: Síntese das políticas públicas nacionais relacionadas à CDB (entre 1994 e 2012) (continua)

\begin{tabular}{|c|c|c|}
\hline $\begin{array}{c}\text { Política } \\
\text { Pública/ } \\
\text { Instrumentos }\end{array}$ & $\begin{array}{c}\text { Ato Legal/ } \\
\text { Data }\end{array}$ & Descrição \\
\hline \multirow{2}{*}{$\begin{array}{c}\text { PRONABIO/ } \\
\text { PROBIO/ } \\
\text { FUNBIO }\end{array}$} & $\begin{array}{c}\text { Decreto } \\
1.354 / 1994\end{array}$ & $\begin{array}{l}\text { Por meio deste Decreto o Governo brasileiro estabelece o Programa } \\
\text { Nacional da Diversidade Biológica-PRONABIO, por meio do Decre- } \\
\text { to } 1354 \text {, de } 29 \text { de dezembro de } 1994 \text { com o objetivo de implementar } \\
\text { a CDB no Brasil. O Decreto estabelece a Comissão Coordenadora } \\
\text { do Programa, com a finalidade de coordenar, acompanhar e avaliar } \\
\text { as ações propostas. Para obter fundos para implementar o Programa, } \\
\text { o Governo iniciou negociações com o GEF para receber recursos de } \\
\text { doação. A partir de então foi iniciado o primeiro projeto brasileiro } \\
\text { junto ao GEF destinado à execução da CDB, o Projeto de Conser- } \\
\text { vação e Utilização Sustentável da Diversidade Biológica Brasileira - } \\
\text { PROBIO9. }\end{array}$ \\
\hline & $28 / 09 /$ & $\begin{array}{l}\text { No âmbito do PRONABIO é estabelecido o Fundo Brasileiro para a Biodiver- } \\
\text { sidade o FUNBIO10, em } 28 \text { de setembro de 1995, com os recursos provenien- } \\
\text { tes do GEF. O FUNBIO foi criado com o objetivo geral de complementar as } \\
\text { ações do governo para a conservação e o uso sustentável da biodiversidade do } \\
\text { país, em consonância com a CDB. O mesmo processo aconteceu em diversos } \\
\text { outros países signatários da CDB, com a criação de instituições denominadas } \\
\text { Fundos Ambientais, especialmente em países com elevada diversidade biológi- } \\
\text { ca da América Latina e Caribe. Atualmente esses fundos estão reunidos na } \\
\text { RedLAC-Rede de Fundos Ambientais da América Latina e Caribe. Atualmente } \\
\text { o FUNBIO é o gestor financeiro de diversos projetos governamentais para áreas } \\
\text { protegidas com recursos do GEF no Brasil. }\end{array}$ \\
\hline $\begin{array}{l}\text { Sistema Nacional } \\
\text { de Unidades de } \\
\text { Conservação - } \\
\text { SNUC }\end{array}$ & $\begin{array}{c}\text { Lei } \\
9.985 / 2000 \\
\text { e Decreto } \\
4.340 / 2002\end{array}$ & $\begin{array}{l}\text { É instituído o Sistema Nacional de Unidades de Conservação - SNUC. } \\
\text { O SNUC foi resultado de um processo de mais de } 12 \text { anos de di- } \\
\text { scussões no Congresso Nacional. O SNUC estabeleceu e sistematizou } \\
\text { as diversas categorias de manejo de unidades de conservação, no plano } \\
\text { nacional atribuindo à federação, estados e municípios responsabilida- } \\
\text { des iguais de conservação da natureza11. Apesar de ter sido iniciado } \\
\text { anteriormente à CDB, o SNUC incorporou em seu Art. } 2^{\circ} \text { a definição } \\
\text { de diversidade biológica consagrada pela CDB que atribui ao termo } \\
\text { biodiversidade uma amplitude maior, considerando-se desde a variabi- } \\
\text { lidade genética até a diversidade de paisagens12. Além disso, pode ser } \\
\text { considerado como um dos principais instrumentos de internalização } \\
\text { da CDB no momento em que a CDB estabeleceu que "os Estados são } \\
\text { responsáveis pela conservação da sua diversidade biológica e utilização } \\
\text { sustentável dos seus recursos biológicos" e que "a exigência fundamen- } \\
\text { tal para a conservação da diversidade biológica é a conservação in situ } \\
\text { dos ecossistemas e habitats naturais, e a manutenção e recuperação de } \\
\text { populações viáveis de espécies no seu meio"13. }\end{array}$ \\
\hline
\end{tabular}




\begin{tabular}{|c|c|c|}
\hline $\begin{array}{c}\text { Política } \\
\text { Pública/ } \\
\text { Instrumentos }\end{array}$ & $\begin{array}{c}\text { Ato Legal/ } \\
\text { Data }\end{array}$ & Descrição \\
\hline $\begin{array}{l}\text { Política Nacional } \\
\text { de Biodiversidade } \\
\text {-PNB }\end{array}$ & $\begin{array}{c}\text { Decreto } \\
4.339 / 2002\end{array}$ & $\begin{array}{l}\text { Instituição da Política Nacional de Biodiversidade cujos os principais } \\
\text { objetivos são: promover a integração de políticas nacionais do governo } \\
\text { e da sociedade; estimular a cooperação interinstitucional e internacional } \\
\text { para a melhoria da implementação das ações de gestão da biodiversidade; } \\
\text { conhecer, conservar e valorizar a diversidade biológica brasileira; proteger } \\
\text { áreas naturais relevantes; promover o uso sustentável da biodiversidade; } \\
\text { respeitar, preservar e incentivar o uso do conhecimento, das inovações e } \\
\text { das práticas das comunidades tradicionais. A PNB engloba componentes } \\
\text { temáticos articulados com os objetivos e princípios da CDB14 }\end{array}$ \\
\hline \multirow{3}{*}{$\begin{array}{l}\text { PRONABIO/ } \\
\text { CONABIO }\end{array}$} & $\begin{array}{c}\text { Decreto } \\
4.703 / 2003\end{array}$ & $\begin{array}{l}\text { Alteração da proposta do PRONABIO para que este pudesse se tran- } \\
\text { sformar em instância responsável pela coordenação da implementação } \\
\text { da Política Nacional de Biodiversidade, mediante a promoção de siner- } \\
\text { gias entre o Poder Público e a sociedade civil. O novo Decreto, N } 4703 \text {, } \\
\text { de } 21 \text { de maio de } 2003 \text { alterou a comissão coordenadora do PRONA- } \\
\text { BIO para Comissão Nacional da Biodiversidade - CONABIO e definiu } \\
\text { a sua estrutura matricial, com os mesmos componentes da Política Na- } \\
\text { cional de Biodiversidade e sete componentes biogeográficos (os conjun- } \\
\text { tos de biomas brasileiros: Amazônia; Caatinga; Mata Atlântica e Campos } \\
\text { Sulinos; Cerrado e Pantanal; e, Zona Costeira e Marinha). }\end{array}$ \\
\hline & $\begin{array}{c}\text { Decreto } \\
5.092 / 2004 \\
\\
\text { Portarias } \\
\text { MMA: } \\
\mathrm{n}^{\circ} 126 / 2004 \\
\text { e no } 9 / 2007\end{array}$ & $\begin{array}{l}\text { Definição de Áreas Prioritárias por biomas. Uma das principais ações } \\
\text { resultantes do PROBIO foi a promoção das primeiras avaliações das } \\
\text { "áreas prioritárias por biomas” no período de } 1998 \text { a 2000, quando } \\
\text { foram identificadas } 900 \text { áreas e ações prioritárias para a conservação } \\
\text { da biodiversidade na Amazônia; Cerrado e Pantanal; Caatinga; Mata } \\
\text { Atlântica e Campos Sulinos; e Zona Costeira e Marinha. Essas ava- } \\
\text { liações se tornaram instrumentos de planejamento para a conservação } \\
\text { da biodiversidade e foram reconhecidas pelo Decreto No 5092, de } 21 \\
\text { de maio de } 2004 \text { que define regras para a identificação de áreas prio- } \\
\text { ritárias para a conservação, utilização sustentável e repartição dos be- } \\
\text { nefícios da biodiversidade, no âmbito das atribuições do Ministério do } \\
\text { Meio Ambiente. O Decreto define que as áreas serão instituídas por } \\
\text { Portaria do MMA a cada revisão15. Foram elaboradas duas Portarias, } \\
\text { uma reconhecendo o primeiro exercício elaborado entre } 1998 \text { a } 2000 \\
\text { (Portaria MMA no } 126 / 2004 \text { ) e a segunda Portaria que reconheceu a } \\
\text { revisão das áreas com a reedição dos seminários por bioma entre os } \\
\text { anos de } 2005 \text { e } 2006 \text { (Portaria MMA no 9/2007). }\end{array}$ \\
\hline & $\begin{array}{c}\text { Resoluções } \\
\text { CONABIO: } \\
n^{\circ} 03 / 2006 \text { e } \\
\text { no } 06 / 2013\end{array}$ & $\begin{array}{l}\text { Definição de Metas para a Biodiversidade. A CONABIO vem funcio- } \\
\text { nando com composição paritária de } 20 \text { membros entre governo e re- } \\
\text { presentantes da sociedade civil. A CONABIO se manifesta por meio } \\
\text { de Resoluções e uma das mais importantes, em sua dinâmica foi a } \\
\text { Resolução que internalizou as primeiras metas da CDB para o período } \\
2002-2010 \text { (Resolução CONABIO n } 03 \text {, de } 21 \text { de dezembro de 2006) } \\
\text { que dispôs sobre as Metas Nacionais de Biodiversidade para 2010. } \\
\text { Mais recentemente, a Resolução CONABIO no } 06 \text { de } 03 \text { de setembro } \\
\text { de } 2013 \text { internalizou para o país o cumprimento das Metas de Aichi. }\end{array}$ \\
\hline
\end{tabular}




\begin{tabular}{|c|c|c|}
\hline $\begin{array}{c}\text { Política } \\
\text { Pública/ } \\
\text { Instrumentos }\end{array}$ & $\begin{array}{c}\text { Ato Legal/ } \\
\text { Data }\end{array}$ & Descrição \\
\hline $\begin{array}{c}\text { Plano de } \\
\text { Ação para } \\
\text { Implementação da } \\
\text { Política Nacional } \\
\text { da Biodiversidade } \\
\text { - PAN-Bio }\end{array}$ & $\begin{array}{l}\text { Deliberação } \\
\text { CONABIO } \\
n^{\circ} 40 / 2006\end{array}$ & $\begin{array}{l}\text { Formulação do Plano de Ação para Implementação da Política Na- } \\
\text { cional da Biodiversidade, visando implementar e suprir lacunas na ge- } \\
\text { stão da biodiversidade no país, o Governo brasileiro coordenou, entre } \\
2004 \text { e } 2005 \text {, a formulação de um Plano de Ação para a implemen- } \\
\text { tação da PNB, o PAN-Bio. Apesar de ser este atualmente um plano } \\
\text { pouco conhecido, o PAN-Bio representou um importante passo entre } \\
\text { governo e sociedade, para a conservação e utilização sustentável da } \\
\text { nossa biodiversidade16. O PAN-Bio foi aprovado pela CONABIO } \\
\text { em sua } 9^{a} \text { reunião extraordinária (Deliberação CONABIO no } 40 \text {, de } \\
07 \text { de fevereiro de 2006). A pretensão, nesse caso, era que, a partir do } \\
\text { envolvimento entre as distintas esferas de governo, promover graus } \\
\text { diferenciados de responsabilidade entre os mesmos, que estimulassem } \\
\text { a descentralização das ações previstas, gerando oportunidades para } \\
\text { solução dos problemas identificados e o seu equacionamento local } \\
\text { e regional a partir das diretrizes e prioridades propostas17. O PAN- } \\
\text { Bio vem sendo, desde então, a base para a elaboração dos Planos de } \\
\text { Ação de Espécies Ameaçadas de Extinção coordenados pelo Instituto } \\
\text { Chico Mendes de Conservação da Biodiversidade. Nesse contexto já } \\
\text { foram realizados trinta e sete planos de fauna e dois planos de flora18. }\end{array}$ \\
\hline $\begin{array}{c}\text { Plano Estratégico } \\
\text { Nacional de Áreas } \\
\text { Protegidas - } \\
\text { PNAP }\end{array}$ & $\begin{array}{c}\text { Decreto } \\
5.758 / 2006\end{array}$ & $\begin{array}{l}\text { Instituição do PNAP. Em conjunto com o SNUC, o Decreto } \\
5.758 / 2006 \text { que institui o PNAP, compõe o que se poderia designar } \\
\text { como uma Política Nacional para as Áreas Protegidas19. O PNAP } \\
\text { foi elaborado em resposta à decisão da COP7 quando foi aprovado } \\
\text { o PoWPA. A principal estratégia do PNAP foi o estabelecimento de } \\
\text { um "sistema abrangente de áreas protegidas, ecologicamente repre- } \\
\text { sentativo, efetivamente manejado e integrado a áreas terrestres e ma- } \\
\text { rinhas até } 2015 \text { " (data apontada na época do PoWPA). O PNAP bu- } \\
\text { scou integrar as unidades de conservação (SNUC) às terras indígenas } \\
\text { e terras quilombolas, além de reservas legais e áreas de preservação } \\
\text { permanente, identificadas no PNAP como elementos integradores da } \\
\text { paisagem. O PNAP representou um instrumento inovador de políti- } \\
\text { ca pública, principalmente no momento em que ficou evidenciado o } \\
\text { papel das áreas protegidas para a melhoria da qualidade de vida das } \\
\text { populações locais e combate à pobreza para assegurar a proteção da } \\
\text { biodiversidade20. Em 2014, após a aprovação pela CONABIO das } \\
\text { metas brasileiras referentes às Metas de Aichi, o PNAP deverá voltar a } \\
\text { ser discutido com maior ênfase para a conservação da biodiversidade } \\
\text { em respostas às metas que dizem respeito a um número mais abran- } \\
\text { gente de áreas protegidas (ver item a seguir). }\end{array}$ \\
\hline $\begin{array}{l}\text { Instituto Chico } \\
\text { Mendes de } \\
\text { Conservação } \\
\text { da Biodiversidade }\end{array}$ & $\begin{array}{l}\text { Lei n }{ }^{\circ} \\
11.516 / \\
2007\end{array}$ & $\begin{array}{l}\text { Criação do ICMBIO. A Lei n }{ }^{\circ} 11.516 \text {, de } 28 \text { de agosto de } 2007 \text { criou } \\
\text { o Instituto Chico Mendes de Conservação da Biodiversidade - ICM- } \\
\text { BIO com a finalidade principal de executar ações da política nacional } \\
\text { de unidades de conservação, relativas à proposição, implantação, ge- } \\
\text { stão, proteção, fiscalização e monitoramento das UCs federais. }\end{array}$ \\
\hline
\end{tabular}




\begin{tabular}{|c|c|c|}
\hline $\begin{array}{c}\text { Política } \\
\text { Pública/ } \\
\text { Instrumentos }\end{array}$ & $\begin{array}{c}\text { Ato Legal/ } \\
\text { Data }\end{array}$ & Descrição \\
\hline $\begin{array}{l}\text { Política } \\
\text { Nacional de } \\
\text { Desenvolvimento } \\
\text { Sustentável } \\
\text { dos Povos e } \\
\text { Comunidades } \\
\text { Tradicionais - } \\
\text { PNPCT }\end{array}$ & $\begin{array}{c}\text { Decreto } \\
6.040 / 2007\end{array}$ & $\begin{array}{l}\text { Instituição da Política Nacional de Desenvolvimento Sustentável dos } \\
\text { Povos e Comunidades Tradicionais pelo qual foi estabelecida também } \\
\text { a Comissão Nacional de Desenvolvimento Sustentável dos Povos e } \\
\text { Comunidades Tradicionais - CNPCT, para coordenar a implemen- } \\
\text { tação a Política. Além disso, o decreto traz a definição de: Povos e Co- } \\
\text { munidades Tradicionais; Territórios Tradicionais e Desenvolvimento } \\
\text { Sustentável e veio a ser a referência para a aplicação do instrumento } \\
\text { da "Bolsa Verde". }\end{array}$ \\
\hline $\begin{array}{c}\text { Programa } \\
\text { de Apoio à } \\
\text { Conservação } \\
\text { Ambiental "Bolsa } \\
\text { verde" }\end{array}$ & $\begin{array}{c}\text { Lei } \\
\text { 12.512/2011 } \\
\\
\text { Decreto } \\
7.572 / 2011\end{array}$ & $\begin{array}{l}\text { Criação do Bolsa Verde. A Lei no 12.512/2011 criou o Programa de } \\
\text { Apoio à Conservação Ambiental e o Programa de Fomento às Ativi- } \\
\text { dades Produtivas Rurais, regulamentados pelo Decreto no } 7572 / 2011 \text {, } \\
\text { e representam um dos incentivos que o governo federal implantou, } \\
\text { visando erradicar a pobreza e beneficiar povos e comunidades tradi- } \\
\text { cionais que conservam os recursos naturais. Estes compõem o Plano } \\
\text { Brasil Sem Miséria coordenado pelo Ministério de Desenvolvimento } \\
\text { Social21. Conhecido como "Bolsa Verde", o Programa de Apoio à } \\
\text { Conservação Ambiental é também um desdobramento da PNPCT, } \\
\text { beneficiando famílias residentes em florestas nacionais, reservas extra- } \\
\text { tivistas ou reservas de desenvolvimento sustentável federais e assen- } \\
\text { tamentos ambientalmente diferenciados, além de territórios ocupados } \\
\text { por ribeirinhos, extrativistas, populações indígenas, quilombolas e ou- } \\
\text { tras comunidades tradicionais. Segundo dados de dezembro de } 2013 \\
\text { do MMA22, o Bolsa Verde atendeu a } 51,2 \text { mil famílias e corresponde } \\
\text { a um investimento da ordem de R } \$ 70 \text { milhões. Atualmente, alcança } \\
65 \text { Unidades de Conservação federais e mais } 767 \text { projetos de assenta- } \\
\text { mento do Incra23. }\end{array}$ \\
\hline $\begin{array}{c}\text { Política Nacional } \\
\text { de Gestão } \\
\text { Territorial e } \\
\text { Ambiental de } \\
\text { Terras Indígenas } \\
\text { - PNGAT }\end{array}$ & $\begin{array}{c}\text { Decreto } \\
7.747 / 2012\end{array}$ & $\begin{array}{l}\text { Instituição da PNGAT. O Decreto no } 7.747 \text {, de } 5 \text { de junho de } 2012 \text {, } \\
\text { instituiu a PNGAT com o objetivo de promover e garantir a proteção, } \\
\text { recuperação, conservação e o uso sustentável dos recursos naturais } \\
\text { das terras e territórios indígenas. Além disso, procura assegurar a in- } \\
\text { tegridade do patrimônio indígena, a melhoria da qualidade de vida e } \\
\text { as condições plenas de reprodução física e cultural das atuais e futuras } \\
\text { gerações dos povos indígenas, respeitando sua autonomia sociocultu- } \\
\text { ral. É organizada em } 7 \text { eixos: proteção territorial e dos recursos natu- } \\
\text { rais; governança e participação indígena; áreas protegidas, unidades de } \\
\text { conservação e terras indígenas; prevenção e recuperação de danos am- } \\
\text { bientais; uso sustentável de recursos naturais e iniciativas produtivas } \\
\text { indígenas; propriedade intelectual e patrimônio genético; capacitação, } \\
\text { formação, intercâmbio e educação ambiental. A implementação do } \\
\text { PNAP, PNPCT e a PNGAT, em conjunto tenderá a apoiar o Governo } \\
\text { brasileiro no cumprimento das Metas de Aichi e as respectivas metas } \\
\text { nacionais. }\end{array}$ \\
\hline
\end{tabular}


Como pode ser observado no Quadro anterior e, segundo Irving,

os esforços dirigidos para a construção de um arcabouço jurídico e institucional às áreas protegidas transformou o país em ícone de inovação em políticas de proteção da natureza, na América Latina.

Esse avanço vem sendo obtido, principalmente, a partir do estabelecimento e regulamentação do Sistema Nacional de Unidades de Conservação - SNUC, do Plano Estratégico Nacional de Áreas Protegidas - PNAP, da Política Nacional de Desenvolvimento Sustentável dos Povos e Comunidades Tradicionais - PNPCT ${ }^{59}$ e mais recentemente, da Política Nacional de Gestão Territorial e Ambiental de Terras Indígenas - PNGAT. Mas esse arcabouço legal inovador vem exigindo também novas institucionalidades e, o aprimoramento do processo de participação social para a conservação da biodiversidade, em escala nacional.

Não se pode também negligenciar que, além de todos os esforços mencionados, o país se caracteriza por elevada extensão territorial sob alguma forma de proteção, conforme ilustrado na Tabela 1, a seguir, que sistematiza os atuais percentuais de Unidades de Conservação e Terras Indígenas em cada um dos biomas brasileiros.

Tabela 1: Percentual de áreas protegidas por bioma no Brasil (incluindo Unidades de Conservação ${ }^{60}$ e Terras indígenas)

\begin{tabular}{|c|c|c|c|c|c|c|c|}
\hline $\begin{array}{c}\text { Biomas } \\
\text { Áreas } \\
\text { Protegidas }\end{array}$ & Amazônia & Caatinga & Cerrado & $\begin{array}{c}\text { Mata } \\
\text { Atlântica }\end{array}$ & Pampa & Pantanal & $\begin{array}{c}\text { Área } \\
\text { Marinha }\end{array}$ \\
\hline $\begin{array}{c}\text { Terra } \\
\text { Indígena }\end{array}$ & $22,2 \%$ & $0,3 \%$ & $4,1 \%$ & $0,5 \%$ & $0,5 \%$ & $1,8 \%$ & - \\
\hline $\begin{array}{c}\text { UC Uso } \\
\text { Sustentável }\end{array}$ & $16,3 \%$ & $6,3 \%$ & $5,1 \%$ & $6,5 \%$ & $2,4 \%$ & $1,5 \%$ & $1,4 \%$ \\
\hline $\begin{array}{c}\text { UC Proteção } \\
\text { Integral }\end{array}$ & $9,8 \%$ & $1,1 \%$ & $3,1 \%$ & $2,4 \%$ & $0,3 \%$ & $2,9 \%$ & $0,1 \%$ \\
\hline Totais & $48,3 \%$ & $7,7 \%$ & 12,3 & 9,45 & $3,2 \%$ & $6,2 \%$ & $1,5 \%$ \\
\hline
\end{tabular}

Fonte: MMA, 2014 e Funai, $2012^{61}$

Essa tabela ilustra a complexidade do desafio a ser enfrentado nos próximos anos. E, mesmo com todos os esforços do Brasil para internalizar a CDB, estes são ainda insuficientes para equacionar a maior parte dos problemas ambientais associadas a esse debate no Brasil, um país de dimensões continentais também sujeito a inúmeras tensões sociais e sob forte pressão de desenvolvimento. Por outro lado, os compromissos assumidos pelo país no âmbito da Convenção podem induzir ações de políticas públicas para o enfrentamento desses problemas, inclusive contribuindo para a sensibilização da sociedade brasileira para a importância da conservação da biodiversidade.

\section{As Metas de Aichi: obstáculos e desafios na Perspectiva de um país emergente}

O delineamento de metas tem sido reconhecido como dispositivo essencial para a avaliação de compromissos globais. E, no caso da CDB, um primeiro conjunto de metas foi estabelecido na COP6 com a

59 IRVING, M. A. Áreas protegidas e inclusão social: uma equação possível em políticas públicas de proteção da natureza no Brasil? Sinais Sociais, Rio de Janeiro, v. 4, n. 12, p. 122-147, jan/abril 2010.

60 Segundo a Lei 9.985, de 18 de julho de 2000 que cria o Sistema Nacional de Unidades de Conservação - SNUC, as UCs se dividem em dois grandes grupos de categorias de manejo - as UCs de proteção Integral em que os recursos naturais podem ser usados da forma indireta: uso público, recreação, pesquisa, educação ambiental e as UCs de uso sustentável, cujos recursos naturais podem ser utilizados de forma direta e sustentável e, ao mesmo tempo, serem conservados.

61 MINISTÉRIO DO MEIO AMBIENTE. Cadastro nacional de unidades de conservação. Disponível em: < www.mma.gov.br/cadastro_uc>. Acesso em: 11 fev. 2014. E FUNAI. Shapefile de terras indigenas. Disponível em: < http://www.funai.gov.br/index.php/ shape>. Acesso em: 01 ago. 2012. 
aprovação do denominado Plano Estratégico para o período 2002-2010. Este primeiro Plano Estratégico foi delineado para orientar a implementação da Convenção em nível nacional, regional e global com o propósito de controlar a perda da biodiversidade e assegurar a repartição justa e equitativa dos benefícios advindos da biodiversidade. No entanto, em 2010, as avaliações realizadas no âmbito da CDB apontaram que o Plano Estratégico 2002 -2010 não havia tido o êxito esperado com relação aos compromissos assumidos. De acordo com essa avaliação consolidada no documento elaborado pelo Secretariado da CDB, "Panorama da Biodiversidade Global 3", a meta acordada pelos governos em 2002 em, "atingir até 2010 uma redução significativa da taxa atual de perda de biodiversidade em níveis global, regional e nacional como uma contribuição para a diminuição da pobreza e para o benefício de toda a vida na Terra" não havia ainda sido alcançada $^{62}$. O documento destaca ainda algumas razões para esse fracasso:

- As espécies antes apontadas com risco de extinção estão, em geral, mais próximas da extinção;

- a abundância de espécies de vertebrados, com base nas populações avaliadas, caiu quase um terço, entre 1970 e 2006, e continuava caindo, especialmente nas regiões neotropicais;

- áreas de habitat naturais continuavam a diminuir em extensão e integridade, apesar de alguns sucessos em diminuir o ritmo da destruição;

- a agrobiodiversidade continua sendo perdida;

- as cinco principais pressões que causam diretamente a perda de biodiversidade continuavam no mesmo nível ou até mais drásticas; a pegada ecológica da humanidade excedeu a capacidade biológica da Terra e tem aumentado constantemente desde que a meta de biodiversidade para 2010 foi traçada.

O documento ressalta ainda que, apesar de se ter fracassado na redução significativa da taxa de perda de biodiversidade, as ações desenvolvidas, individualmente, pelos países signatários, resultaram em uma desaceleração do processo. No entanto, o documento também menciona que, principalmente nos países menos desenvolvidos, ainda existem lacunas importantes a serem enfrentadas para conter as pressões sobre a biodiversidade e implementar a CDB. Da mesma forma, não tem havido integração suficiente entre as políticas públicas com relação à biodiversidade com as demais estratégias e programas governamentais, o que por sua vez, se reflete na perda progressiva de biodiversidade em escala global ${ }^{63}$.

Apesar do reconhecimento dessas fragilidades, os acordos multilaterais, desde a década de 1980, são reconhecidos como essenciais em apoio às políticas de conservação da biodiversidade. Um argumento a favor desta afirmação é que em 1992, durante o Congresso Mundial de Parques da IUCN ${ }^{64}$ foi estabelecido o objetivo de se proteger $10 \%$ da área terrestre global ${ }^{65}$, o que influenciou as negociações do Plano Estratégico da CDB para o período de 2002 - $2010^{66}$. E embora na época os países signatários não concordassem em incorporar formalmente esse percentual de áreas protegidas como meta a ser atingida, estabeleceu-se pacto não formal entre os mesmos e esta meta passou a orientar o debate, principalmente no caso daqueles em

62 MINISTÉRIO DO MEIO AMBIENTE. Panorama da biodiversidade global 3. Brasília: Secretariado da Convenção Sobre Diversidade Biológica - SCDB, 2010.

63 MINISTÉRIO DO MEIO AMBIENTE. Panorama da biodiversidade global 3. Brasília: Secretariado da Convenção Sobre Diversidade Biológica - SCDB, 2010.

64 A IUCN realiza dois grandes eventos na área de conservação ambiental mundial. A cada quatro anos são realizados os Congressos Mundiais de Conservação em que os membros da organização (entre governo, setor público, organizações não governamentais, empresas, agências da ONU e organizações sociais) se unem para discutir, debater e elaborar resoluções que visam alavancar ações de conservação no planeta. E a cada 10 anos a IUCN realiza também os Congressos Mundiais de Parques que por sua vez objetivam discutir especificamente a situação das áreas protegidas e elaborar diretrizes para o próximo período.

65 MCNEELY, J. A. International Union for the conservation of nature and world wildlife fund. In: WORLD CONGRESS ON NATIONAL PARKS AND PROTECTED AREAS, 4., 1992. Report... Gland, Switzerland, 1992.

66 SOUTULLO, A.; CASTRO, M.; URIOS, V. Linking political and scientifically derived targets for global biodiversity conservation: Implications for the expansion of the global network of protected areas. Diversity and Distributions, Curitiba, v. 14, n. 4, p. 604-613, july 2008. 
desenvolvimento, que foram impulsionados nesta direção por campanhas de organizações internacionais não governamentais, com o apoio do Banco Mundial. Sendo assim, de acordo com o documento Protected Planet Report 2012, lançado pela CDB, houve um aumento global de 48\% em área protegida entre 1990 e $2012^{67}$. Estimativas globais mais recentes apontam percentuais de 14,6\% para as áreas terrestres e 2,8\% para os oceanos ${ }^{68}$.

Dessa forma, apesar de não se ter atingido globalmente a meta central do Plano Estratégico 2002 - 2010, a evidência do aumento de áreas protegidas no mundo foi, provavelmente, um ponto central para encorajar a $\mathrm{CDB}$ na proposição de um novo Plano Estratégico com novas metas a serem cumpridas para o período subsequente.

Consequentemente, durante a COP10, em 2010, foi aprovado o Plano Estratégico 2011 - 2020 para a década seguinte. O escopo central do Plano são 20 metas, denominadas de "Metas de Aichi" "O lançamento, pela ONU, da "década da biodiversidade" durante a realização da sua $65^{a}$ reunião de cúpula em 22 de setembro de 2010, fizeram com que o tema passasse a estar no centro das discussões políticas, e a "década" passou a ser entendida exatamente como estratégica para o cumprimento das Metas de Aichi ${ }^{70}$.

No contexto nacional, é fundamental que se enfatize o papel cronológico do Brasil na implementação do Plano Estratégico 2002 - 2010. O país foi o responsável pela criação de 74\% das áreas criadas no planeta, entre 2003 e $2008^{71}$, principalmente no bioma Amazônia, como forma de conter os altos índices de desmatamento observados à época (ver Tabela 1). Foi também o primeiro país que internalizou, em 2006, o Plano, por meio de ato legal (Resolução da Comissão Nacional de Biodiversidade - $\mathrm{CONABIO}^{72}$ ). Na Resolução CONABIO foram definidas 51 metas nacionais para a biodiversidade projetadas para o horizonte de 2010 relacionadas às metas globais da CDB para o mesmo período, algumas das quais mais ambiciosas do que aquelas expressa na própria Convenção. Estas metas estabeleceram que, até 2010, pelo menos 30\% da Amazônia e 10\% dos demais biomas estariam sob a forma de unidades de conservação, incluindo a zona costeira e marinha. Em 2010, o Ministério do Meio Ambiente ${ }^{73}$ realizou uma avaliação sobre o cumprimento das metas nacionais revelando que em 2010 o país já dispunha de, aproximadamente, os mesmos percentuais de áreas protegidas que possui hoje (16,8\% para as áreas terrestres e 1,5\% da área marinha $\left.{ }^{74}\right)$ o que se deve a uma paralisação no ritmo de criação de áreas protegidas no país, desde então.

67 Dados do documento Protected Planet Report 2012 demonstram que em 2010 já se registrava 12,7\% de território terrestre mundial sob alguma forma de proteção. Os dados no entanto não são foram os mesmos para as áreas marinhas, que, na mesma época, englobavam apenas 1,6\% em área protegida. BERTZKY, B. et al. Protected planet report 2012: tracking progress towards global targets for protected areas. IUCN: Gland, Switzerland; UNPE-WCMC: Cambridge, UK, 2012.

68 Dados atualizados do Banco de dados mundiais sobre áreas protegidas: UNEP-WCMC, 2013. Protected Planet on line. $<$ http://www.unep-wcmc.org/protected-planet-_530.html>. Vale ressaltar, no entanto que esses percentuais demonstram apenas a cobertura de áreas protegidas, não levando em conta o desempenho e efetividade que ainda estão longe de ser convincentes, segundo ANTHAMATTEN, P. \& HAZEN, H. Changes in the Global Distribution of Protected Areas, 2003-2012. The Professional Geographer, in press. 2014.

69 O Plano Estratégico 2011-2020 possui: base lógica que relaciona a biodiversidade ao bem estar humano, aos Objetivos do Milênio e à redução da pobreza; cenário que transcende 2020, estabelecendo a situação desejada para 2050, com "a biodiversidade valorizada, conservada, restaurada e utilizada com sabedoria"; missão que expressa a intenção urgente de agir para se alcançar os objetivos de 2020; 5 objetivos estratégicos; 20 metas (de Aichi); e, mecanismos para a sua implementação (Decisão X/2 da CDB) $<$ https://www.cbd.int/decisions/cop/?m=cop-10>.

$70<$ https://www.cbd.int/2011-2020/>.

71 JENKINS, C. N.; JOPPA, L. Expansion of the global terrestrial protected area system. Biological Conservation, London, v. 142 , p. 2166-2174, May 2009.

72 A Comissão Nacional da Biodiversidade - CONABIO foi criada pelo Decreto nº 4.703, de 21 de maio de 2003 - Ver Quadro 3. A CONABIO se manifesta por meio de resoluções, sendo uma das mais importantes a resolução que internalizou as primeiras metas da CDB para o período 2002-2010 - Resolução CONABIO nº 03, de 21 de dezembro de 2006.

73 MINISTÉRIO DO MEIO AMBIENTE. Quarto relatório nacional para a convenção sobre diversidade biológica. Brasília: MMA, 2010.

74 Ver tabela 1. MMA. Cadastro Nacional de Unidades de Conservação. Disponível em: <www.mma.gov.br/cadastro_uc>. Acesso em: 11 fev. 2014 
Da mesma maneira, o país teve um papel importante na definição das ambiciosas Metas de Aichi ${ }^{75}$. Durante as negociações na COP10 em 2010, a delegação brasileira foi uma das mais ativas na busca por um consenso sobre metas mais audaciosas então propostas, principalmente em relação às áreas protegidas — a Meta $11^{76}$. No Brasil, o Sistema Nacional de Unidades de Conservação - SNUC já incorpora, desde 2000, áreas de uso sustentável destinadas às populações tradicionais como é o caso das categorias de manejo "Reserva Extrativista" e "Reserva de Desenvolvimento Sustentável"77. Associado ao SNUC, o pais dispõe ainda do Plano Estratégico Nacional de Áreas Protegidas - PNAP, que desde 2006, vem enfatizando a importância das Terras Indígenas e Terras de Quilombos para a conservação da biodiversidade, o que vem contribuindo para uma situação confortável da delegação brasileira, na proposição de metas e percentuais mais audaciosos para as áreas protegidas do que muitos dos países envolvidos.

Vale também enfatizar que, frente às atuais Metas de Aichi para 2020, o governo brasileiro estabeleceu, em 2013, as metas nacionais no âmbito da CONABIO (ver Quadro 3). A Meta 11 nacional foi ampliada para incluir, além das unidades de conservação, as demais áreas protegidas legalmente instituídas no país, como as Terras Indígenas e as áreas previstas no Código Florestal — Áreas de Preservação Permanentes (APPs) e Reservas Legais ${ }^{78}$. Além disso, essa meta contempla critérios como representatividade, efetividade e conectividade. Nesse sentido, especial destaque foi atribuído ao bioma Amazônia, a saber:

Até 2020, serão conservadas, por meio de unidades de conservação previstas na Lei do SNUC e outras categorias de áreas oficialmente protegidas, como Áreas de Preservação Permanente - APPs, reservas legais e terras indígenas com vegetação nativa, pelo menos 30\% da Amazônia, $17 \%$ de cada um dos demais biomas terrestres e $10 \%$ de áreas marinhas e costeiras, principalmente áreas de especial importância para biodiversidade e serviços ecossistêmicos, assegurada e respeitada a demarcação, regularização e a gestão efetiva e equitativa, visando garantir a interligação, integração e representação ecológica em paisagens terrestres e marinhas mais amplas.

Dessa forma, a consecução da Meta 11 envolve desafio complexo e de longo prazo, uma vez que esta não somente assegurou os compromissos relativos à criação de novas áreas protegidas mas também a sua efetividade, eficácia da gestão, representatividade ecológica, governança equitativa e conectividade. E tanto a Meta 11 global quanto a meta nacional da CONABIO reforçam esses elementos. Alguns pesquisadores defendem até mesmo que deve haver uma

interpretação holística da Meta 11 como uma maneira para que a comunidade global utilize as áreas protegidas para alterar as atuais tendências inaceitáveis na perda de biodiversidade global ${ }^{79}$.

No entanto, no Brasil, apesar dos esforços para os avanços significativos na ampliação da área sob proteção na forma de unidades de conservação até 2010, parece haver ainda um descompasso entre esses esforços de conservação nos diferentes biomas, o que tende a comprometer o elemento de "representatividade" previsto na Meta 11 (tabela 1). Além disso, o desempenho do país está muito aquém do esperado com relação à almejada efetividade na gestão dessas áreas ${ }^{80}$. E, mesmo no bioma Amazônia, onde já se teria atingido a meta, um relatório atual elaborado pelo Tribunal de Contas da União ${ }^{81}$, demonstra grande desar-

75 LOPOUKHINE, N.; DIAS, B. F. S. What does target 11 really mean? Parks, Gland, Switzerland, v. 18, n. 1, p. 5-8, sept 2012. $76 \mathrm{Na}$ COP10 em Nagoya, a delegação brasileira iniciou as negociações ressaltando a importância de se elevar os percentuais de áreas protegidas para pelo menos $20 \%$ para o ambiente terrestre e $15 \%$ para o ambiente marinho (observação da própria autora presente às negociações). As reinvindicações da sociedade civil brasileira à época eram de $20 \%$ para ambos os ambientes (ver: <http://www.portaldomeioambiente.org.br/mudancas-climaticas/5452-sociedade-civil-apresenta-ao-governo-sua-posicao-para-acop-10cdb $>$ ).

77 A Lei 9.985 de 18 de julho de 2000 institui o Sistema Nacional de Unidades de Conservação da Natureza

78 COMISSÃO NACIONAL DE BIODIVERSSIDADE. Resolução CONABIO n. 06, de 3 de setembro de 2013. Disponível em: < http://portaldabiodiversidade.sp.gov.br/files/2014/06/Metas-Nacionais-CONABIO.pdf>. Acesso em: 03 mar. 2015.

79 WOODLEY, S. et al. Meeting Aichi target 11: what does success look like for protected area systems? Parks, Gland, Switzerland, v. 18, n. 1, p.23-36, sept 2012.

80 MINISTÉRIO DO MEIO AMBIENTE. Quarto relatório nacional para a convenção sobre diversidade biológica. Brasília: MMA, 2010.

81 Em 2012 o Tribunal de Contas da União realizou uma Auditoria Operacional sobre Governança das Unidades de Conservação 
ticulação entre as diversas esferas de governo na implementação dos instrumentos legais acordados, o que prejudica a efetividade da gestão e a conservação da biodiversidade nessas áreas. Segundo o TCU, o SNUC não é ainda coordenado de maneira integrada ${ }^{82}$, apesar de o texto desse relatório admitir avanços na gestão das unidades de conservação federais após a criação do ICMBIO ${ }^{83}$. O TCU aponta também a necessidade de implementação do Plano Estratégico Nacional de Áreas Protegidas - PNAP ${ }^{84}$, o que parece imprescindível frente à nova Meta 11 nacional.

Nesse sentido, vale lembrar que o texto do PNAP tem como princípio a valorização de demais áreas protegidas, para além das unidades de conservação, e reconhece a complementariedade entre as mesmas, como uma estratégia para a conservação da diversidade biológica e sociocultural. O texto do PNAP reconhece também o papel das terras indígenas e dos territórios quilombolas para a conservação da biodiversidade. As APPs e as Reservas Legais são também consideradas, por esse instrumento, como essenciais para o planejamento da paisagem, no âmbito da abordagem ecossistêmica, sendo consideradas estratégicas para a conectividade entre fragmentos naturais e as próprias áreas protegidas. O PNAP, porém, não foi ainda implementado embora os compromissos que enuncia sejam essenciais para a implementação e monitoramento da nova meta nacional ${ }^{85}$.

Uma leitura crítica sobre as políticas públicas em implementação no Brasil com relação à conservação da biodiversidade indica, assim, a existência de um extenso arcabouço legal envolvendo Leis e Decretos que nem sempre dialogam entre si. Mas, apesar disso, os decretos referentes às políticas dirigidas aos povos indígenas e populações tradicionais podem ser considerados um avanço pela abordagem das questões sociais envolvidas na gestão de áreas protegidas. Estes podem significar um salto qualitativo para a conservação da biodiversidade. No entanto, quando se avalia a implementação institucional dos instrumentos de políticas públicas, não parece haver a integração necessária entre os órgãos que os coordenam e as ações em curso ${ }^{86}$.

Assim, a "esquizofrenia", ou fragmentação, de políticas públicas e, a dificuldade de planejamento estratégico nas próprias esferas envolvidas, tem representado fonte de conflitos históricos ${ }^{87}$ no processo de conservação da biodiversidade. E segundo Irving:

Este fato tem gerado problemas graves como a criação de Unidades de Conservação em sobreposição as Terras Indígenas (fato marcante no caso amazônico), o mesmo território sendo priorizado, simultaneamente, pelas políticas vinculadas a proteção da natureza, a reforma agraria, ao agronegócio, a energia e a infraestrutura. E ainda mais problemático, o confronto direto entre as prioridades de proteção da natureza e as estratégias desenvolvimentistas consolidadas em investimentos governamentais, claramente ilustradas pelo Plano de Aceleração do Crescimento (PAC). Assim, o mesmo território é priorizado em políticas públicas para fins contraditórios. E em um contexto no qual as informações sobre essas iniciativas não são democratizadas, resta um passivo de conflito, insatisfação e frustração

do Bioma Amazônia em que constatou que "as UCs no bioma Amazônia não estão atingindo plenamente os resultados esperados, uma vez que há um baixo aproveitamento do potencial econômico, social e ambiental dessas áreas. Isso decorre principalmente de fragilidades na gestão que dificultam: o uso público; as concessões florestais; o fomento às atividades extrativistas; e as atividades de pesquisas e monitoramento" (ACÓRDÃO No 3101/2013 - TCU - Plenário). Disponível em: <://www.camara.gov.br/internet/ comissao/index/mista/orca/tcu/>. Acesso em: 03 mar. 2015.

82 O TCU colocou uma série de recomendações ao Governo e uma determinação ao MMA: "determinar ao Ministério do Meio Ambiente (MMA), com base no art. 250, II, do RI/TCU, que adote e comunique ao Tribunal de Contas da União, no prazo de até 180 (cento e oitenta) dias, as providências adotadas para o exercício da coordenação do Sistema Nacional de Unidades de Conservação da Natureza, em cumprimento ao art. 6º II, da Lei 9.985/2000" (ACÓRDÃO No 3101/2013 - TCU - Plenário). Disponível em: <http://www.camara.gov.br/internet/comissao/index/mista/orca/tcu/>. Acesso em: 03 mar. 2015.

83 Ver Quadro 3.

84 Ver Quadro 3.

85 PRATES, A. P. L.; SOUSA, N. Panorama das áreas protegidas no Brasil. In: BENSUSAN, N.; PRATES, A. P. L. (Ed.). A diversidade cabe na unidade? Áreas protegidas no Brasil. Brasília: IEB Mil Folhas, 2014. p82-119.

86 Como podemos ver no relatório realizado pelo TCU em 2013. (ACÓRDÃO No 3101/2013 - TCU - Plenário). Disponível em: <http://www.camara.gov.br/internet/comissao/index/mista/orca/tcu/>. Acesso em: 03 mar. 2015.

87 IRVING, M. A. et al. Governança e políticas públicas: desafios para gestão de parques nacionais no Brasil. In: FONTAINE, G.; VLIET, G. V.; PASQUIS, R. (Org.). Politicas ambientales y gobernabilidad en America Latina. Quito: FLACSO, 2007. p. 79-103. 
coletiva. Essas práticas governamentais estão no cerne das principais tensões sociais locais e também na dificuldade de entendimento do real papel das áreas protegidas para o país 88 .

Com base nesse pressuposto, é importante mencionar estudo recente que buscou mapear os principais conflitos ambientais no mundo e concluiu que entre 945 casos estudados em 78 países, o Brasil foi o terceiro no ranking, com 58 casos de conflitos, empatando nessa avaliação com a Nigéria e perdendo no ranking apenas para a Índia e a Colômbia ${ }^{89}$. E, segundo o estudo, os conflitos no país estão principalmente vinculados aos projetos de infraestrutura que impactam, sistematicamente, à integridade das áreas naturais. Estes projetos envolvem grandes obras, como a construção de hidrelétricas, que confrontam interesses dentre o movimento social e o setor privado (empreiteiras e agrobusiness), cujas atividades interferem sobre as áreas protegidas. E, nesse caso, os mais afetados pelo processo são exatamente as populações tradicionais, indígenas, quilombolas e agricultores familiares, grupos socialmente vulneráveis.

Mas o próprio processo de globalização desempenha também um papel importante na política global de conservação ambiental, com efeitos evidentes no Brasil, porque os processos políticos e econômicos globais influenciam a forma como as áreas protegidas são entendidas e discutidas pela sociedade e como são priorizadas nas agendas políticas ${ }^{90}$. Além disso, o estabelecimento de sistemas de áreas protegidas vem sendo, cada vez mais, entendido como um desafio complexo diante dos inúmeros interesses e/ou conflitos envolvidos. E, sendo assim,

Antes, relativamente simples, a tarefa de projetar áreas protegidas para ser um conjunto representativo dos ecossistemas do mundo tornou-se progressivamente mais complexa cientificamente. Trata-se de uma crescente sofisticação na biologia da conservação com novos insights sobre ecologia natural e o reconhecimento de novas ameaças em grande parte provocadas pelas atividades humanas. As áreas protegidas integram todas essas ameaças e, nesse sentido, refletem nosso mundo em mudança91.

São, portanto inúmeros os desafios a serem enfrentados nos próximos anos. Como ampliar e expandir o conjunto de áreas protegidas no Brasil diante do modelo de desenvolvimento vigente no qual essas áreas vêm sendo interpretadas, frequentemente, como "entraves" ao crescimento do país? Como tornar essas áreas efetivas com orçamentos limitados e o baixo efetivo de profissionais qualificados na gestão pública no país diante da dimensão do desafio $?^{92}$ Como transformar a sociedade em aliada do processo de conservação da biodiversidade?

Não se pode negligenciar, assim, que o desafio para o cumprimento das Metas de Aichi constitui compromisso global, mas tem significado ainda maior para o Brasil, um país megadiverso que busca alcançar parâmetros ascendentes de crescimento econômico mas também se situa em uma das primeiras posições no ranking global de conflitos ambientais.

Nesse caso, o futuro das áreas protegidas (sejam elas unidades de conservação segundo o SNUC, ou parte de um conjunto mais amplo, segundo o PNAP), vai depender do alcance de ações governamentais para a implementação das políticas vigentes, bem como da integração e sinergia entre as políticas públicas,

88 IRVING, M. A. Áreas protegidas e inclusão social: uma equação possível em políticas públicas de proteção da natureza no Brasil? Sinais Sociais, Rio de Janeiro, v. 4, n. 12, p. 122-147, jan/abril 2010.

89 O estudo foi traduzido em um Atlas on line (Global Atlas of Environmental Justice) e conduzido pela Organização não Governamental EJOLT (Environmental Justice Organizations, Liabilities and Trade) com coordenação da Universidade Autônoma de Barcelona. Disponível em: <http://www.ejolt.org/2014/03/global-atlas-of-environmental-conflicts-launched-in-brussels-2/>.Acesso em: 03 mar. 2015). Segundo o estudo a exploração mineral, o desmatamento e a disputa por terras e água estão entre os maiores motivos de conflitos ambientais do mundo.

90 ANTHAMATTEN, Peter; HAZEN, Helen. Changes in the global distribution of protected areas, 2003-2012. The Professional Geographer, p. 1-9, 24 jun. 2014.

91 Com essa frase Thomas Lovejoy sintetiza bem os desafios atuais para o estabelecimento de áreas protegidas no mundo.

(LOVEJOY, T. E. Protected areas: a prism for a changing world. TREE, London, v. 21, p. 329-333, june 2006).

92 ACÓRDÃO No 3101/2013 - TCU - Plenário. Disponível em:

<http://www.camara.gov.br/internet/comissao/index/mista/orca/tcu/>. 
no âmbito do Governo Brasileiro. Nesse sentido, Medeiros e colaboradores ${ }^{93}$ defendem que o sucesso das políticas públicas de conservação da biodiversidade depende do

aperfeiçoamento do sistema em termos conceituais e operacionais, da integração harmônica de Políticas Públicas e, sobretudo, do fortalecimento de canais de diálogo entre os diferentes atores sociais e setores nacionais e internacionais, e da compreensão da perspectiva social associada à proteção da natureza.

Os argumentos desses autores reafirmam ainda que

este é um processo em franca construção, com desfecho imprevisível, mas que pode vir a estabelecer ou fortalecer modos de ação pautados, cada vez mais, na democracia e equidade política e social ${ }^{94}$.

Assim, este é um processo que se constrói progressivamente no país e que tenderá a se consolidar a partir de um maior engajamento da sociedade e de políticas públicas mais articuladas. Nesse caso, as ações de conservação da biodiversidade não podem estar restritas apenas aos ministérios de meio ambiente de cada país, mas devem ter rebatimento em todos os demais setores governamentais ${ }^{95}$.

Além disso, nesse desafio é essencial a participação ativa da sociedade na formulação de políticas públicas que procurem efetivar os direitos econômicos, sociais e culturais, bem como o fomento às novas formas de produção e de consumo voltadas para o desenvolvimento sustentável e que garantam o pleno exercício das liberdades e capacidades humanas ${ }^{96}$. Respeitadas essas condições e pelas razões anteriormente discutidas, o Brasil poderá vir a se tornar um exemplo para os demais países signatários da $\mathrm{CDB}$, contribuindo, a partir das lições aqui aprendidas, para uma nova leitura sobre a conservação da biodiversidade, no plano global.

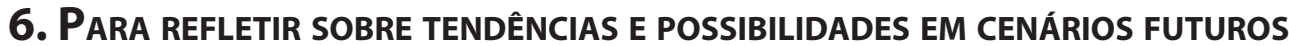

Para se refletir sobre tendências em médio e em longo prazo, é importante que se considere que os desafios para se atingir as Metas de Aichi não são, no entanto, restritos a Meta 11. No âmbito da Convenção vem sendo realizados inúmeros levantamentos junto aos países signatários para se avaliar a importância da Convenção sobre a Biodiversidade na sociedade, as implicações do Plano Estratégico 2011-202097, bem como as dificuldades em se atingir as referidas metas. E, mesmo não sendo esta uma Convenção vinculante, ou seja, que não impõem sanções aos países que não cumprem suas metas e diretrizes, segundo Machado98:

Há que se lembrar que os tratados, confiando-se na boa-fé e nos costumes, devem ser: pacta sunt servanda. Portanto isso não tira a obrigação de se obedecer a normas válidas e deve-se lembrar que toda norma é a imagem que se quer de um mundo melhor, ou seja o "dever ser". Segundo ainda o autor: o que podemos concluir dessa afirmação é que a "responsabilidade ambiental” por parte dos Estados é de teor político, e não totalmente legal. É de fato uma obrigação natural, fruto dos ideais éticos humanos. Ou seja, são tentativas políticas, em boa fé, para solução de problemas ambientais, as quais respeitam a soberania, porém modificam sua essência para um bem maior.

93 MEDEIROS, R.; IRVING, M. A.; GARAY, I. Áreas protegidas no Brasil: interpretando o contexto histórico para pensar a inclusão social. In: IRVING, M. A. (Org.). Áreas protegidas e inclusão social: construindo novos significados. Rio de Janeiro: Aquarius, 2006.

94 MEDEIROS, R.; IRVING, M. A.; GARAY, I. Áreas protegidas no Brasil: interpretando o contexto histórico para pensar a inclusão social. In: IRVING, M. A. (Org.). Áreas protegidas e inclusão social: construindo novos significados. Rio de Janeiro: Aquarius, 2006.

95 RANDS, M. R. W. et al. Biodiversity conservation: challenges beyond. Science, London, v. 329, n. 5997, p. 1298-1303, sept. 2010. 96 WALKER, P. B. A construção do direito ao desenvolvimento e sua aplicação mediante as políticas públicas de sustentabilidade. Rev. Bras. de Políticas Públicas, Brasília, v. 1, n. 1, p. 159-190, jan./jun. 2011.

97 Cada país signatário indica ao Secretariado da CDB diversos pontos focais técnicos do Ministério do Meio Ambiente ou demais ministérios para responder e prestar informações sobre os variados temas da Convenção. O ponto focal político que sempre é um representante do Ministério das Relações Exteriores. O questionário mencionado foi respondido pela autora em março/2013.

98 MACHADO, F. P. M. Soberania e meio ambiente: a adequação do direito internacional às novas necessidades de gestão ambiental e os mecanismos da ONU para resolução de conflitos. PRISMAS: Dir., Pol. Pub. e Mundial, Brasília, v.4, n, 1, p. 123-150, jan.jul. 2007. 
Pelos argumentos apresentados, o Brasil foi e continua sendo um ator chave na implementação de diretrizes da Convenção sobre Diversidade Biológica. E, no país, são inúmeros os instrumentos jurídicos que orientam as políticas públicas no que diz respeito à conservação da biodiversidade com foco em áreas protegidas. No entanto, frente às novas metas estabelecidas, (tanto as Metas de Aichi quanto as metas nacionais em seu rebatimento), é fundamental que se busque um "olhar" mais estratégico e integrado sobre esses instrumentos. Além disso, seria imprescindível que as estratégias de desenvolvimento adotadas pelo país pudessem harmonizar os interesses econômicos com aqueles dirigidos à conservação da biodiversidade, uma vez que estes não são excludentes e nem contraditórios, em tese.

Nesse campo de debate não se pode negligenciar que o Sistema Nacional de Unidades de Conservação da Natureza - SNUC constitui uma das propostas para a conservação da biodiversidade mais avançadas do mundo. Sua concepção transcende a proteção da biodiversidade pois possibilita vários usos do solo e dos recursos naturais. E, ao articular o SNUC com os demais instrumentos de políticas públicas como o Plano Estratégico Nacional de Áreas Protegidas - PNAP, a Política Nacional de Desenvolvimento Sustentável dos Povos e Comunidades Tradicionais - PNPCT e a Política Nacional de Gestão Territorial e Ambiental de Terras Indígenas - PNGATI, o país estará colocando em prática os preceitos e diretrizes da CDB, ao mesmo tempo em que poderá demonstrar aos demais ser possível integrar à conservação da biodiversidade, o compromisso de inclusão social e, o combate à pobreza, contribuindo também para o atingimento das Metas do Milênio.

Assim, para que as áreas protegidas sejam valorizadas e consolidadas, no futuro, um dos principais desafios tende a ser despertar o interesse da sociedade brasileira para a importância do patrimônio natural e cultural protegido por essas áreas, de maneira que o investimento nestas possa também significar benefícios e qualidade de vida para todos os brasileiros. As áreas protegidas poderiam se tornar, por essa via, alternativas efetivas para potencializar a geração de emprego e renda, a melhoria da qualidade de vida, sem prejuízo à conservação da biodiversidade. Nesse encaminhamento se estaria construindo um ciclo virtuoso a partir de políticas públicas integradas que priorizem a conservação da biodiversidade e a inclusão social, garantindo que a sociedade seja beneficiada e entenda o sentido do patrimônio natural como um diferencial para o próprio desenvolvimento do país.

\section{REFERÊNCIAS}

ANTHAMATTEN, Peter; HAZEN, Helen. Changes in the global distribution of protected areas, 20032012. The Professional Geographer, p. 1-9, 24 jun. 2014.

BERTZKY, B. et al. Protected planet report 2012: tracking progress towards global targets for protected areas. IUCN: Gland, Switzerland; UNPE-WCMC: Cambridge, UK, 2012.

BENSUSAN, Nurit (Ed.) et al. Biodiversidade: para comer, vestir ou passar no cabelo? São Paulo: Peirópolis, 2006.

BENSUSAN, Nurit. Os pressupostos biológicos do Sistema Nacional de Unidades de Conservação. In: BENJAMIN, Antonio Herman (Coord.). Direito ambiental das áreas protegidas: o regime jurídico das unidades de conservação. Rio de Janeiro: Forense Universitária, 2001. p. 164-189.

BRANDON, K. et al. Conservação brasileira: desafios e oportunidades. Megadiversidade, Rio de Janeiro, v. 1, n. 1, p. 7-13, jul. 2005.

BRASIL. Decreto n. 4.339, de 22 de agosto de 2002. Política Nacional de Biodiversidade - PNB. Disponível em: <http://www.planalto.gov.br/ccivil_03/decreto/2002/D4339.htm>. Acesso em: 03 mar. 2015. 
BRASIL. Decreto n. 4.340, de 22 de agosto de 2002. Sistema Nacional de Unidades de Conservação da Natureza - SNUC. Disponível em: <http://www.planalto.gov.br/ccivil_03/decreto/2002/d4340.htm>. Acesso em: 03 mar. 2015.

BRASIL. Decreto n. 5.092, de 21 de maio de 2004. Regras para identificação de áreas prioritárias para a conservação, utilização sustentável e repartição dos benefícios da biodiversidade, no âmbito das atribuições do Ministério do Meio Ambiente. Disponível em: < http://www.planalto.gov.br/ccivil_03/_ato2004-2006/2004/ decreto/d5092.htm>. Acesso em: 03 mar. 2015.

BRASIL. Decreto n. 5.758, de 13 de abril de 2006. Plano Estratégico Nacional de Áreas Protegidas. Disponível em: <http://www.planalto.gov.br/ccivil_03/_Ato2004-2006/2006/Decreto/D5758.htm>. Acesso em: 03 mar. 2015.

BRASIL. Decreto n. 6.040, de 7 de fevereiro de 2007. Política Nacional de Desenvolvimento Sustentável dos Povos e Comunidades Tradicionais - PNPCT. Disponível em: < http://www.planalto.gov.br/ccivil_03/_ ato2007-2010/2007/decreto/d6040.htm>. Acesso em: 03 mar. 2015.

BRASIL. Decreto n. 7.644, de 16 de dezembro de 2011. Programa de Fomento às Atividades Produtivas Rurais. Disponível em: <http://www.planalto.gov.br/ccivil_03/_ato2011-2014/2011/Decreto/D7644.htm>. Acesso em: 03 mar. 2015.

BRASIL. Decreto n. 7.747, de 5 de junho de 2012. Política Nacional de Gestão Territorial e Ambiental de Terras Indígenas - PNGAT. Disponível em: <http://www.planalto.gov.br/ccivil_03/_ato2011-2014/2012/decreto/d7747.htm>. Acesso em: 03 mar. 2015.

BRASIL. Lei n. 9.985, de 18 de julho de 2000. Disponível em: <http://www.planalto.gov.br/ccivil_03/leis/ 19985.htm>. Acesso em: 03 mar. 2015.

BRASIL. Lei n. 12.512, de 14 de outubro de 2011. Programa de Apoio à Conservação Ambiental e o Programa de Fomento às Atividades Produtivas Rurais. Disponível em: < http://www.planalto.gov.br/ccivil_03/_ ato2011-2014/2011/Lei/L12512.htm>. Acesso em: 03 mar. 2015.

BROCKINGTON, D.; IGOE, J. Eviction for conservation: a global overview. Conservation \& Society, Australia, v. 4, n. 3, p. 424-70, jun 2006.

BUTCHART, Stuart. H. M. et al. Global biodiversity: indicators of recent declines. Science, London, v. 328, n.5982, p. 1164-1168, may 2000.

COAD, L. et al. Progress on the convention on biological diversity's 2010 and 2012 targets for protected area coverage. In: LOOKING TO THE FUTURE OF THE CBD PROGRAMME OF WORK ON PROTECTED AREAS, 2009, Jeju Island. Proceedings... Republic of Korea: Jeju Island, 2009. p. 14-17.

COAD, L. et al. Progress towards the CBD protected area management effectiveness targets. Parks, Gland, Switzerland, v. 19, n. 1, march 2013.

CONVENTION ON BIOLOGICAL DIVERSITY (CBD). Resourcing the Aichi biodiversity targets: a first assessment of the resources required for implementing the strategic plan for biodiversity 2011-2020. Report of the High-Level Panel on Global Assessment of Resources for Implementing the Strategic Plan for Biodiversity 2011-2020. 2012. Disponível em: < http://www.cbd.int/doc/meetings/fin/hlpgar-sp-01/official/ hlpgar-sp-01-01-report-en.pdf> Acesso em: 12 jul. 2014.

CORRIGAN, C.; HAY-EDIE, T. A toolkit to support conservation by indigenous peoples and local communities: building capacity and sharing knowledge for indigenous peoples and community conserved territories and areas (iccas). UNEP-WCMC: Cambridge, UK, 2013.

DERANI, C. Direito ambiental econômico. São Paulo: Max Limonad, 1997. 
FIELDING, G. et al. What is the convention on biological diversity, and what is it trying to achieve? Journal of Conservation Biology 3065, London, v. 1, p. 17, [Online] 2009. Disponível em: http://myweb.dal.ca/ bworm/Fielding_etal_CBD.pdf.

GLOWKA, L.; BURHENNE-GUILMIN, F.; SYNGE, H. A guide to the convention on biological diversity. 2. ed. IUCN: Gland; Cambridge, 1996.

IRVING, M. A. Áreas protegidas e inclusão social: uma equação possível em políticas públicas de proteção da natureza no Brasil? Sinais Sociais, Rio de Janeiro, v. 4, n. 12, p. 122-147, jan/abril 2010.

IRVING, M. A.; MATOS, K. Gestão de parques nacionais no Brasil: projetando desafios para a implementação do Plano Nacional Estratégico de Áreas Protegidas. Floresta e Ambiente, Rio de Janeiro, v. 13, n. 2, p. 89-96, nov 2006.

IRVING, M. A. et al. Governança e políticas públicas: desafios para gestão de parques nacionais no Brasil. In: FONTAINE, G.; VLIET, G. V.; PASQUIS, R. (Org.). Politicas ambientales y gobernabilidad en America Latina. Quito: FLACSO, 2007.p. 79-103.

JENKINS, C. N.; JOPPA, L. Expansion of the global terrestrial protected area system. Biological Conservation, London, v. 142, p. 2166-2174, may 2009.

KOTHARI, A. et al. Recognising and supporting territories and areas conserved by indigenous peoples and local communities: global overview and national case studies. Montreal, Canada: Secretariat of the Convention on Biological Diversity, 2012. (CBD Technical Series, 64).

LOVEJOY, T. E. Protected areas: a prism for a changing world. TREE, London, v. 21, p. 329-333, june 2006.

LEWINSOHN, T. (Coord.) Avaliação do estado do conhecimento da biodiversidade Brasileira. Brasília: Ministério do Meio Ambiente - MMA, 2006. (Série Biodiversidade, 15).

LOPOUKHINE, N. et al. 2012. Protected areas: providing natural solutions to 21 st century challenges. Sapiens, [Online], v. 5, n.2, p. 116-131, august 2012. Available at: <http://sapiens.revues.org/1254>. Last access on: 08 apr. 2014.

LOPOUKHINE, N.; DIAS, B. F. S. What does target 11 really mean? Parks, Gland, Switzerland, v. 18, n. 1, p. 5-8, sept. 2012.

MACHADO, F. P. M. Soberania e meio ambiente: a adequação do direito internacional às novas necessidades de gestão ambiental e os mecanismos da ONU para resolução de conflitos. PRISMAS: Dir., Pol. Pub. e Mundial, Brasília, v.4, n, 1, p. 123-150, jan_jul. 2007.

MCNEELY, J. A. International Union for the conservation of nature and world wildlife fund. In: WORLD CONGRESS ON NATIONAL PARKS AND PROTECTED AREAS, 4., 1992. Report... Gland, Switzerland, 1992.

MEDEIROS, R.; IRVING, M. A.; GARAY, I. Áreas protegidas no Brasil: interpretando o contexto histórico para pensar a inclusão social. In: IRVING, M. A. (Org.). Áreas protegidas e inclusão social: construindo novos significados. Rio de Janeiro: Aquarius, 2006.

MERCADANTE, M. Uma década de debate e negociação: a história da elaboração da lei do SNUC. In: HERMAN, A. B. (Coord.). Direito ambiental das áreas protegidas. Rio de Janeiro: Forense Universitária, 2001. p. 190-231.

MEYNEN, Nick; TEMPER, Leah. Global atlas of environmental conflicts launched in Brussels. Environmental Justice Organisations, Liabilities and Trade, 24 march 2014. Available at: <http://www.ejolt.org/2014/03/ global-atlas-of-environmental-conflicts-launched-in-brussels-2>. Last access on: 03 mar. 2015. 
MINISTÉRIO DO MEIO AMBIENTE. Diretrizes e prioridades do plano de ação para implementação da Política Nacional da Biodiversidade. Brasília: MMA, 2006. (Série Biodiversidade, 22).

MINISTÉRIO DO MEIO AMBIENTE. O Sistema Nacional de Conservação da Natureza - SNUC. Brasília: MMA, 2011.

MINISTÉRIO DO MEIO AMBIENTE. Panorama da biodiversidade global 3. Brasilia: Secretariado da Convenção Sobre Diversidade Biológica - SCDB, 2010.

MINISTÉRIO DO MEIO AMBIENTE. Quarto relatório nacional para a convenção sobre diversidade biológica. Brasília: MMA, 2010.

MINISTÉRIO DO MEIO AMBIENTE. Sumário executivo das áreas prioritárias para a conservação, utilização sustentável e repartição de benefícios da biodiversidade brasileira. Brasília: MMA, 2007.

MITTERMEIER, R. A. et al. Hotspots revisited: earth's biologically richest and most endangered terrestrial ecoregions. Local: CEMEX, 2005.

OLIVEIRA, Elizabeth; IRVING, Marta de Azevedo. Convenção sobre diversidade biológica pós Nagoya: desafios para a mídia em um país de megadiversidade. Razón y Palabra, Local, v. 16, n. 75, feb./abr. 2011. Disponible en: <www.razonypalabra.org.mx/N/N75/varia_75/.../40_Oliveira_V75.pdf>. Acceso en: 03 mar. 2015.

PHILLIPS, A. A short history of the international system of protected area management categories. Local: IUCN/ WCPA Task Force on Protected Area Categories, 2007.

PIMM, S. L. et al. Can we defy nature's end? Science, London, v. 293, n. 5538, p. 2207-2208, sept. 2001.

PRATES, A. P. L.; SOUSA, N. Panorama das áreas protegidas no Brasil. In: BENSUSAN, N.; PRATES, A. P. L. (Ed.). A diversidade cabe na unidade? Áreas protegidas no Brasil. Brasilia: IEB Mil Folhas, 2014. p 82-119.

PROTECTED Planet on line. Available at: <http://www.protectedplanet.net/>. Last access on: 03 mar. 2015.

RANDS, M. R. W. et al. Biodiversity conservation: challenges beyond. Science, London, v. 329, n. 5997, p. 1298-1303, sept. 2010.

REAKA-KUDLA, M. L.; WILSON D. E.; WILSON, E. O. (Ed.). Biodiversity II: understanding and protection our biological resources. Washington D. C.: Joseph Henry Press, 1997.

REPORT of the Colloquium on the Role of ICCAs in Achieving the Aichi Targets. Hyderabad, India, 13 october 2012. Available at: <http://www.cbd.int/doc/pa/icca-day-report-en.pdf>. Last access on: 03 mar. 2015.

RODE, J.; WITTMER, H.; MANNS, F. Implementation guide for Aichi target 11: a TEEB perspective. Berlim: German Federal Agency for Nature Conservation (BfN), 2012.

STOLTON, S.; DUDLEY, N. (Ed.). Arguments for protected areas: multiple benefit for conservation and use. London: Earthscan, 2010.

TEN KATE, K. Science and the convention on biological diversity. Science, London, v. 295, n. 5564, p. 2371 2372, mar. 2002.

WALKER, P. B. A construção do direito ao desenvolvimento e sua aplicação mediante as políticas públicas de sustentabilidade. Rev. Bras. de Políticas Públicas, Brasília, v. 1, n. 1, p. 159-190, jan./jun. 2011.

WOODLEY, S. et al. Meeting Aichi target 11: what does success look like for protected area systems? Parks, Gland, Switzerland, v. 18, n. 1, p.23-36, sept. 2012. 
WORLD PARKS CONGRESS, 5., 2003, Durban, South Africa. Message... Durban: WPC, 2003. [CDRom.]

\section{(FOOTNOTES DAS TABELAS)}

1 Clearing-House Mechanism (CHM) da CDB é uma rede mundial de governos e organizações parceiras que facilitam a cooperação científica e técnica por meio da troca de informações <http://www.chm-cbd.net/ >.

2 O Fundo Global para o Meio Ambiente (Global Environment Facility - GEF) foi criado em 1991 como um Programa Piloto do banco Mundial para auxiliar os países em desenvolvimento na implementação de projetos que buscassem soluções para as preocupações globais em relação à proteção dos ecossistemas e à biodiversidade. Desde 1992, o GEF é um mecanismo de cooperação internacional com a finalidade de prover recursos adicionais e fundos concessionais para cobrir custos incrementais em projetos que beneficiem o meio ambiente global <http://www.thegef.org/gef/home $>$.

3 <http://www.thegef.org/gef/>.

4 Abreviatura do inglês Access and Benefit-sharing.

5 As MOPs começaram a acontecem na mesma periodicidade das COPs, sempre uma semana antes de cada Conferência.

6 O Conselho Nacional do Meio Ambiente - CONAMA é o órgão consultivo e deliberativo do Sistema Nacional do Meio Ambiente-SISNAMA, instituído pela Lei 6.938/81, que dispõe sobre a Política Nacional do Meio Ambiente, regulamentada pelo Decreto 99.274/90 e presidido pelo Ministério do Meio Ambiente.

7 Ver site da Iniciativa Lifeweb: <http://lifeweb.cbd.int/>.

8 Ver maiores detalhes sobre as EBSAS em: <http://ebsa.cbd.int/>.

9 MINISTÉRIO DO MEIO AMBIENTE. Quarto relatório nacional para a convenção sobre diversidade biológica. Brasília: MMA, 2010.

$10<$ http://www.funbio.org.br/>.

11 MERCADANTE, M. Uma década de debate e negociação: a história da elaboração da lei do SNUC. In: HERMAN, A. B. (Coord.). Direito ambiental das áreas protegidas. Rio de Janeiro: Forense Universitária, 2001. p. 190-231.

12 BENSUSAN, Nurit. Os pressupostos biológicos do Sistema Nacional de Unidades de Conservação. In: BENJAMIN, Antonio Herman (Coord.). Direito ambiental das áreas protegidas: o regime jurídico das unidades de conservação. Rio de Janeiro: Forense Universitária, 2001. p. 164-189.

13 MINISTÉRIO DO MEIO AMBIENTE. Convenção sobre diversidade biológica - CDB: Brasília: MMA, 2000. (Série Biodiversidade, 2). Disponível em: <http://www.mma.gov.br/estruturas/sbf_dpg/_arquivos/cdbport.pdf>. Acesso em: 03 mar. 2015.

14 MINISTÉRIO DO MEIO AMBIENTE. Diretrizes e prioridades do plano de ação para implementação da Politica Nacional da Biodiversidade. Brasília: MMA, 2006. (Série Biodiversidade, 22).

15 MINISTÉRIO DO MEIO AMBIENTE. Sumário executivo das áreas prioritárias para a conservação, utilização sustentável e repartição de beneficios da biodiversidade brasileira. Brasília: MMA, 2007.

16 MINISTÉRIO DO MEIO AMBIENTE. Diretrizes e prioridades do plano de ação para implementação da Política Nacional da Biodiversidade. Brasília: MMA, 2006. (Série Biodiversidade, 22).

17 MINISTÉRIO DO MEIO AMBIENTE. Diretrizes e prioridades do plano de ação para implementação da Politica Nacional da Biodiversidade. Brasília: MMA, 2006. (Série Biodiversidade, 22).

$18<$ http://www.icmbio.gov.br/portal/>.

19 BRASIL. Decreto n. 5.758, de 13 de abril de 2006. Plano Estratégico Nacional de Áreas Protegidas. Disponível em: <http://www. planalto.gov.br/ccivil_03/_Ato2004-2006/2006/Decreto/D5758.htm>. Acesso em: 03 mar. 2015.

20 BRASIL. Decreto n. 5.758, de 13 de abril de 2006. Plano Estratégico Nacional de Áreas Protegidas. Disponível em: <http:/ /www. planalto.gov.br/ccivil_03/_Ato2004-2006/2006/Decreto/D5758.htm>. Acesso em: 03 mar. 2015.

21 <http://www.mma.gov.br/desenvolvimento-rural/bolsa-verde e http://www.brasilsemmiseria.gov.br/inclusao-produtiva/ bolsa-verde $>$.

22 <http://www.mma.gov.br/desenvolvimento-rural/bolsa-verde>.

23 O Instituto Nacional de Colonização e Reforma Agrária - INCRA estabelece sob sua jurisdição projetos de reforma agrária criados e reconhecidos pelo Programa Nacional de Reforma Agrária - PNRA (Norma de Execução DT no 69/2008), sendo dois grupos: I - criados pelo Incra por meio de obtenção de terras, na forma tradicional, denominados Projetos de Assentamentos (PA), e ambientalmente diferenciados, denominados Projeto de Assentamento Agroextrativista (PAE), Projeto de Desenvolvimento Sustentável (PDS) e Projeto de Assentamento Florestal (PAF) e II - reconhecidos pelo Incra, criados pelas instituições governamentais para acesso às políticas públicas do PNRA. (grifo nosso) < http://www.incra.gov.br/index.php/reforma-agraria-2/projetos-e-programas-do-incra/relacaode-projetos-de-reforma-agraria $>$. 
Para publicar na revista Brasileira de Políticas Públicas, acesse o endereço eletrônico www.rbpp.uniceub.br

Observe as normas de publicação, para facilitar e agilizar o trabalho de edição. 